Article

\title{
A Transcriptomic Approach to Elucidate the Mechanisms of Gefitinib-Induced Toxicity in Healthy Human Intestinal Organoids
}

\author{
Daniela Rodrigues $^{1, *(D)}$, Bram Herpers ${ }^{2}$, Sofia Ferreira ${ }^{3}$, Heeseung Jo ${ }^{3}$, Ciarán Fisher ${ }^{3}$, Luke Coyle ${ }^{4}$, \\ Seung-Wook Chung ${ }^{4}$, Jos C. S. Kleinjans ${ }^{1}$, Danyel G. J. Jennen ${ }^{1}$ (D) and Theo M. de Kok ${ }^{1}$
}

\section{check for}

updates

Citation: Rodrigues, D.; Herpers, B.; Ferreira, S.; Jo, H.; Fisher, C.; Coyle, L.; Chung, S.-W.; Kleinjans, J.C.S.; Jennen, D.G.J.; de Kok, T.M. A Transcriptomic Approach to Elucidate the Mechanisms of Gefitinib-Induced Toxicity in Healthy Human Intestinal Organoids. Int. J. Mol. Sci. 2022, 23, 2213. https:// doi.org/10.3390/ijms23042213

Academic Editor: Mathieu Vinken

Received: 1 February 2022

Accepted: 15 February 2022

Published: 17 February 2022

Publisher's Note: MDPI stays neutral with regard to jurisdictional claims in published maps and institutional affiliations.

Copyright: (c) 2022 by the authors Licensee MDPI, Basel, Switzerland. This article is an open access article distributed under the terms and conditions of the Creative Commons Attribution (CC BY) license (https:// creativecommons.org/licenses/by/ $4.0 /)$
1 Department of Toxicogenomics, GROW School for Oncology and Developmental Biology, Maastricht University, 6229 ER Maastricht, The Netherlands; j.kleinjans@maastrichtuniversity.nl (J.C.S.K.); danyel.jennen@maastrichtuniversity.nl (D.G.J.J.); t.dekok@maastrichtuniversity.nl (T.M.d.K.)

2 Crown Bioscience Netherlands B.V., J.H. Oortweg 21, 2333 CH Leiden, The Netherlands; bram.herpers@crownbio.com

3 Simcyp Division, Certara UK Limited, Sheffield S1 2BJ, UK; sofia.ferreira1@astrazeneca.com (S.F.); emily.jo@certara.com (H.J.); ciaran.p.fisher@gsk.com (C.F.)

4 Boehringer Ingelheim International GmbH, Pharmaceuticals Inc., Ridgefield, CT 06877, USA; luke.coyle@boehringer-ingelheim.com (L.C.); seung.chung@boehringer-ingelheim.com (S.-W.C.)

* Correspondence: d.rodrigues@maastrichtuniversity.nl

\begin{abstract}
Gefitinib is a tyrosine kinase inhibitor (TKI) that selectively inhibits the epidermal growth factor receptor (EGFR), hampering cell growth and proliferation. Due to its action, gefitinib has been used in the treatment of cancers that present abnormally increased expression of EGFR. However, side effects from gefitinib therapy may occur, among which diarrhoea is most common, that can lead to interruption of the planned therapy in the more severe cases. The mechanisms underlying intestinal toxicity induced by gefitinib are not well understood. Therefore, this study aims at providing insight into these mechanisms based on transcriptomic responses induced in vitro. A 3D culture of healthy human colon and small intestine (SI) organoids was exposed to $0.1,1,10$ and $30 \mu \mathrm{M}$ of gefitinib, for a maximum of three days. These drug concentrations were selected using physiologically-based pharmacokinetic simulation considering patient dosing regimens. Samples were used for the analysis of viability and caspase 3/7 activation, image-based analysis of structural changes, as well as RNA isolation and sequencing via high-throughput techniques. Differential gene expression analysis showed that gefitinib perturbed signal transduction pathways, apoptosis, cell cycle, FOXO-mediated transcription, p53 signalling pathway, and metabolic pathways. Remarkably, opposite expression patterns of genes associated with metabolism of lipids and cholesterol biosynthesis were observed in colon versus SI organoids in response to gefitinib. These differences in the organoids' responses could be linked to increased activated protein kinase (AMPK) activity in colon, which can influence the sensitivity of the colon to the drug. Therefore, this study sheds light on how gefitinib induces toxicity in intestinal organoids and provides an avenue towards the development of a potential tool for drug screening and development.
\end{abstract}

Keywords: gefitinib; human intestinal organoids; molecular mechanisms; transcriptomics; toxicity

\section{Introduction}

Gefitinib is a chemotherapeutic agent that belongs to the group of tyrosine kinase inhibitors (TKIs) and that selectively inhibits the activity of receptor tyrosine kinases (RTKs) [1]. In the case of gefitinib, it selectively inhibits epidermal growth factor receptor (EGFR) kinase [2] via competitive inhibition of ATP at the enzyme's catalytic binding site [3]. Gefitinib is especially used in the treatment of locally advanced or metastatic non-small cell lung carcinoma (NSCLC), particularly in cases that derive from mutations in the EGFR gene $[2,4]$. This drug has also shown efficacy in the treatment of cutaneous squamous cell 
carcinoma and advanced cervical cancer [5,6]. After administration, gefitinib is extensively metabolized in an oxidation process that facilitates excretion of the compound and in which the enzymes CYP3A4/5 play an important role [4].

Gefitinib is generally well-tolerated despite some reported adverse effects that can affect approximately $30 \%$ of patients. The known side effects most commonly include skin rashes and diarrhoea (30\%), and less commonly nausea, vomiting and stomatitis/mucositis $(10-25 \%)$ [2,7]. Due to the severity of the gastrointestinal (GI) symptoms among patients taking gefitinib, these patients are required to reduce or even stop their treatment, which hampers their chance of survival. Despite the promise and success of gefitinib in the treatment of cancer as compared with other chemotherapeutics, the mechanism underlying gefitinib-driven intestinal toxicity is not yet fully understood. Studies on the intestinal toxicity induced by gefitinib are still very limited as they focus only on efficacy, side effects and intestinal growth inhibition [8-13] without investigating the molecular responses underlying those adverse events. No previous studies have examined the gene expression responses of intestinal cells towards gefitinib. For these reasons, this study aimed at generating new transcriptomic data to improve understanding about the molecular mechanisms involved in gefitinib-induced intestinal toxicity.

In this study, three-dimensional (3D) innovative cell models of human colon and small intestine (SI) were established as described in our previous work [14] due to their potential in drug-response modulation. The establishment of 3D organoid systems has exponentially increased in recent years as they replicate in vivo cellular organization, behaviour, and cellenvironment interactions more closely than conventional 2D cultures $[15,16]$. 3D intestinal organoids are no exception as they have shown to possess key features of human in vivo intestinal tissue, namely crypt-like structures $[17,18]$. These features have improved the understanding of tissue/organ development, homeostasis, and diseases [19-21], particularly in cancer modulation and anti-cancer drug research. Several studies on cancer research have applied 3D organoids to investigate tumorigenesis, cancer progression and therapeutic screening including brain [22], lung [23], breast [24] or GI organoids [25]. Therefore, $3 \mathrm{D}$ cell culture technologies are promising alternatives to 2D systems in pre-clinical drug development and drug-specific responses studies [15].

Here, we applied 3D colon and SI organoids to investigate gefitinib transcriptomic responses and gain new insights on the molecular mechanisms of the drug toxicity. Responses in colon and SI tissues were compared to establish if their different cell composition, dynamics and function is reflected by distinct gene expression profiles. The exposure concentrations for the in vitro experiments with gefitinib were based on physiologically based pharmacokinetic (PBPK) modelling and simulation to guarantee that the in vitro concentrations of gefitinib reflect patients' dose regimens during chemotherapy [14,26]. Intestinal organoids were exposed to four different concentrations $(0.1,1,10$ and $30 \mu \mathrm{M})$ for three days. After exposure, samples were evaluated for cytotoxicity and characterized for structural/morphological changes by image analysis, which can be associated with gefitinib's mode of action and transcriptomic data. In-depth quantitative RNA-sequencing was performed to investigate changes in the gene expression profiles of treated organoids. We aim to identify differentially expressed genes (DEGs) and the most relevant affected biological pathways that, when compared with functional endpoints, can provide new molecular markers associated with gefitinib effects on the intestinal tissue. These results could be of future relevance in the development and screening of new TKIs and to better predict potential intestinal damages. In the context of the Translational Quantitative System Toxicology (transQST) project [26], the new transcriptomic data will be applied in a QST model to predict GI toxicity caused by drugs. This is a fundamental contribution to transQST as the project aims at improving the understanding of drug safety by developing tools that facilitate the assessment of safety profiles of potential medicines before clinical testing [26]. 


\section{Results}

\subsection{VIVD and PBPK-Based Gefitinib Exposure In Vitro Nominal Concentrations}

The predictive performance of the gefitinib human PBPK model was validated using observed total plasma concentrations from peer-reviewed literature [27], shown in Figure 1. Observed total plasma concentrations of gefitinib were generally captured within the $95 \%$ confidence interval of the simulated plasma concentration-time profile. The validated gefitinib model was then used to predict gefitinib PK after the therapeutic regimen of one daily $250 \mathrm{mg}$ oral dose. The corresponding PK profile of free gefitinib in plasma and jejunum enterocytes are shown in Figure 2 and steady state PK are detailed in Table 1. Free gefitinib concentrations in vivo were of interest as free compound drives the response. Steady state plasma concentrations are achieved after 10 days of one daily dosing of $250 \mathrm{mg}$ oral gefitinib [28]. In plasma, the maximum free concentration reached at steady state $\left(\mathrm{C}_{\text {max,ss }}\right)$ was predicted as $0.03 \mu \mathrm{M}$ and average concentration at steady state $\left(\mathrm{C}_{\mathrm{av}, \mathrm{ss}}\right)$ was predicted as $0.02 \mu \mathrm{M}$. In enterocytes, the predicted free $C_{\max , s s}$ and $C_{a v, s s}$ was $15.38 \mu \mathrm{M}$ and $7.69 \mu \mathrm{M}$, respectively. Fraction of unbound gefitinib in enterocytes was assumed to be 1, i.e., gefitinib is completely unbound in enterocytes. This assumption is likely an overestimation knowing that gefitinib is highly protein bound in plasma $\left(f_{u}=0.064\right)$. However, in the absence of tissue specific data, this assumption allows the in vitro nominal concentrations selected based on predicted unbound in vivo enterocyte concentrations to reach the highest possible therapeutic exposure.
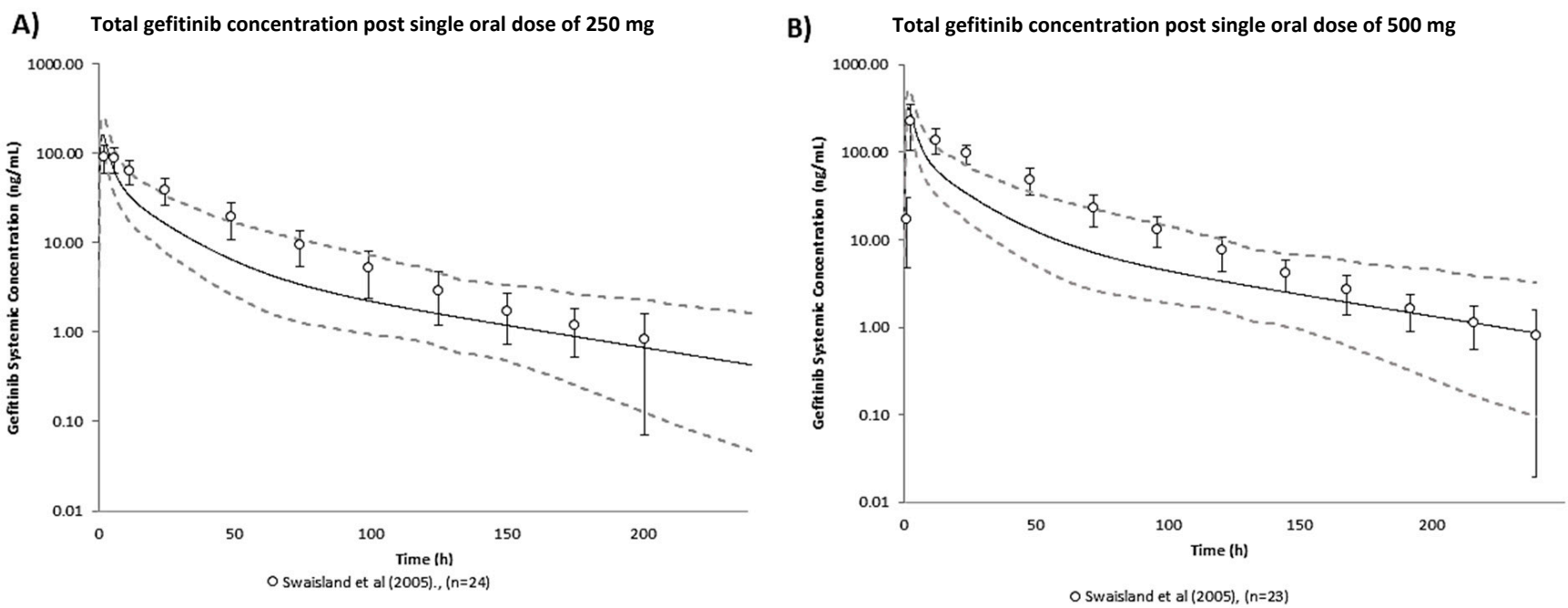

Figure 1. Verification of the gefitinib human PBPK model: predicted geometric mean (solid black line) and observed geometric mean (data points) \pm standard deviation (error bars) of total gefitinib concentration post single oral dose of (A) $250 \mathrm{mg}$ and (B) $500 \mathrm{mg}$ [27]. The dashed lines refer to the predicted 95th percentile range. Virtual population demographic was simulated to be equivalent to the reported study (healthy volunteers, aged 21-57 years old, $0 \%$ female, $n=100$ ). 

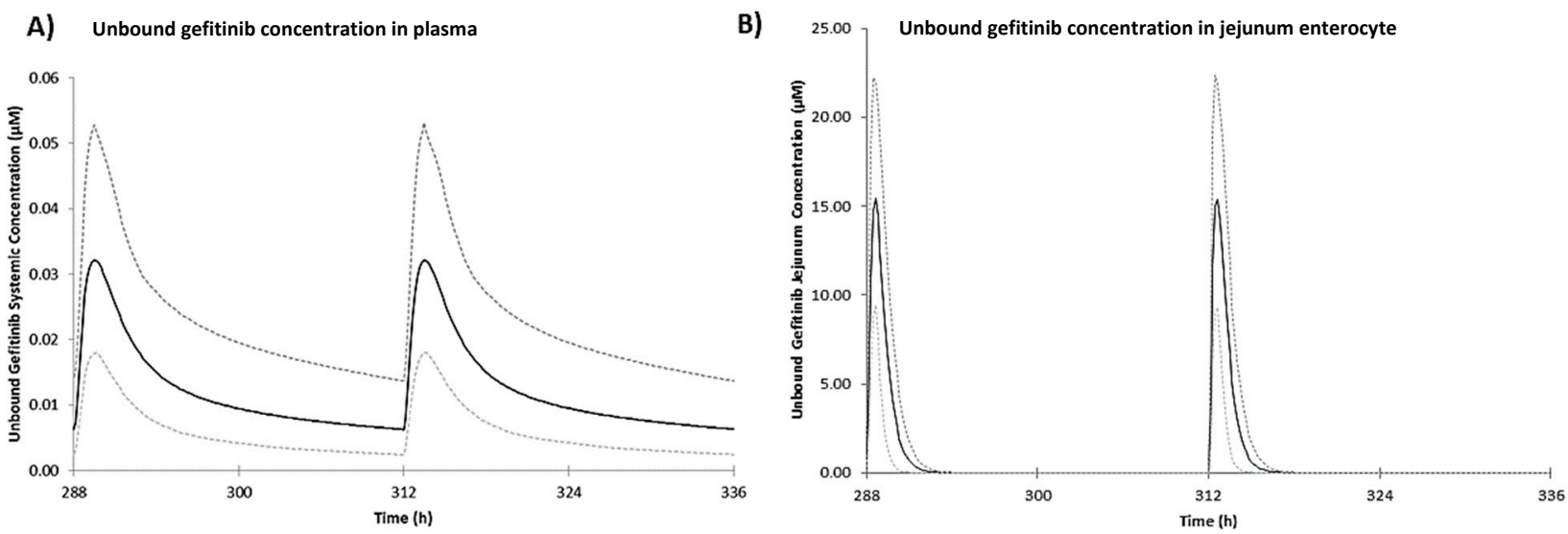

Figure 2. Predicted mean (solid black line) of unbound gefitinib concentration in (A) plasma and (B) jejunum enterocyte for the last two doses during once daily $250 \mathrm{mg}$ oral dose in human over 14 days. The dashed lines refer to the 95th percentile range of the simulated virtual population (healthy volunteers, aged $20-50$ years old, $50 \%$ female, $n=100$ ).

Table 1. VIVD-Based Predictions of in Vitro Human Intestinal Organoid Intracellular Concentrations at Steady State for Different in Vitro Nominal Concentrations. PBPK-predicted in vivo mean gefitinib maximum concentration at steady state $\left(\mathrm{C}_{\max , \mathrm{ss}}\right)$, minimum concentration at steady state $\left(C_{\min , s s}\right)$ and average concentration at steady state $\left(C_{a v, s s}\right)$ for once daily dosing of $250 \mathrm{mg}$ oral gefitinib in healthy volunteers (aged $20-50$ years old, $50 \%$ female, $n=100$ ).

\begin{tabular}{|c|c|c|c|}
\hline \multicolumn{4}{|c|}{ VIVD-based in vitro predictions } \\
\hline $\begin{array}{c}\text { Nominal } \\
\text { concentration }(\mu \mathrm{M})\end{array}$ & \multicolumn{3}{|c|}{ Human intestinal organoid intracellular concentration $(\mu \mathrm{M})$} \\
\hline 0.01 & \multicolumn{3}{|c|}{0.91} \\
\hline 0.1 & \multicolumn{3}{|c|}{9.14} \\
\hline 1 & \multicolumn{3}{|c|}{91.37} \\
\hline 10 & \multicolumn{3}{|c|}{$913.67^{\dagger}$} \\
\hline \multicolumn{4}{|c|}{ PBPK-based in vivo predictions during $250 \mathrm{mg}$ once daily dosing } \\
\hline & $\mathrm{C}_{\mathrm{av}, \mathrm{ss}}(\mu \mathrm{M})$ & $\mathrm{C}_{\max , \mathrm{ss}}(\mu \mathrm{M})$ & $\mathrm{C}_{\min , \mathrm{ss}}(\mu \mathrm{M})$ \\
\hline \multirow{3}{*}{$\begin{array}{c}\text { Total plasma } \\
\text { Unbound plasma } \\
\text { Total and unbound } \\
\text { enterocyte }\end{array}$} & 0.31 & 0.51 & 0.10 \\
\hline & 0.02 & 0.03 & 0.01 \\
\hline & 7.69 & 15.38 & $5.98 \times 10^{-14}$ \\
\hline
\end{tabular}

${ }^{\dagger}$ Prediction based on assumption of non-saturable binding, hence the ratio of nominal to intracellular concentration remains constant; ${ }^{*}$ total and unbound gefitinib in enterocytes assumed equal.

Intracellular gefitinib concentrations in vitro were predicted using VIVD that simulated the human intestinal organoid assay conditions (Table S1). The results of predicted intracellular gefitinib concentrations in a range of nominal concentrations at steady state are presented in Table 1 . The predicted intracellular concentration to nominal concentration ratio was 91.37, which is in line with gefitinib as a highly lipophilic compound $\left(\log \mathrm{P}_{\mathrm{ow}}=4.15\right)$ [29]. A nominal concentration of $0.1 \mu \mathrm{M}$ was predicted to correspond with an intracellular concentration of $9.14 \mu \mathrm{M}$, which is comparable to the predicted in vivo jejunum enterocyte $\mathrm{C}_{\mathrm{av}, \mathrm{ss}}$ of $7.69 \mu \mathrm{M}$ from therapeutic dosing. Therefore, by combining PBPK modelling and VIVD, an in vitro testing strategy that achieved therapeutic tissue exposure was informed.

\subsection{Evaluation of Viability and Apoptosis}

Cell viability was established for colon and SI organoids exposed to $0.1 \mu \mathrm{M}-30 \mu \mathrm{M}$ gefitinib based on measurements of ATP levels and apoptosis reflected by caspases $3 / 7$ 
activation (Figure 3). In colon organoids, there was no significant effect observed in either cell viability or caspase activation for the lower concentration $(0.1 \mu \mathrm{M})$ as compared to the controls (Figure 3A,B). A decrease in viability was first noticeable at $1 \mu \mathrm{M}$, and continued to decrease significantly at $10 \mu \mathrm{M}$ and $30 \mu \mathrm{M}$, in a concentration and time-dependent manner. At the highest concentration and longest time point, viability decreased by more than $60 \%$ (Figure 3A). On the other hand, caspase activation only presented a significant increase after $10 \mu \mathrm{M}$ exposure, particularly after $48 \mathrm{~h}$ and $72 \mathrm{~h}$ (Figure $3 \mathrm{~B}$ ). The experimental condition of $30 \mu \mathrm{M}$ gefitinib at $72 \mathrm{~h}$ indicated a significant activation of apoptotic processes in the colon organoids (600\% caspase activation).
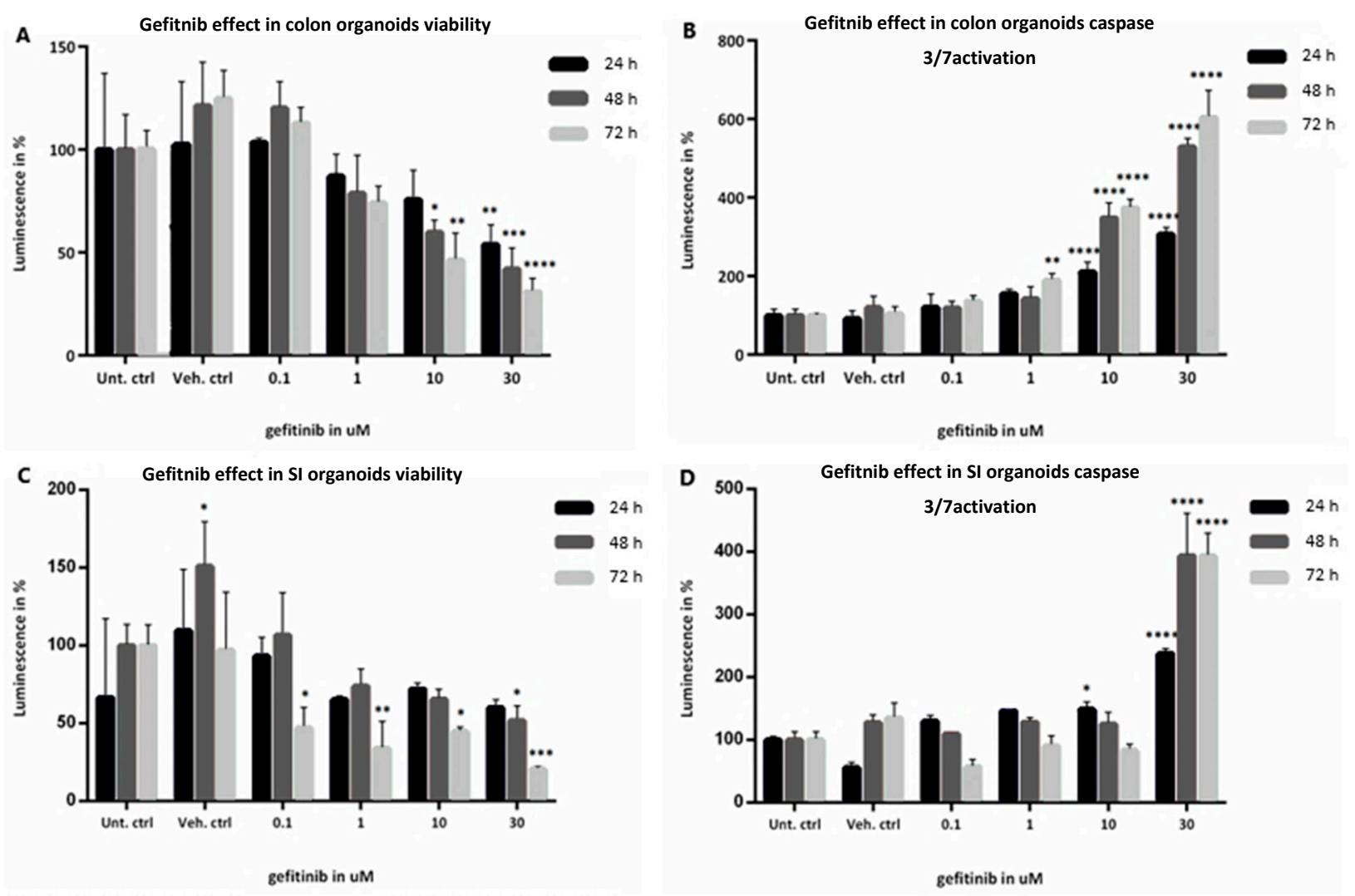

Figure 3. (A-D): Evaluation of viability determined by ATP levels and caspase 3/7 activation of healthy colon (A,B, respectively) and SI (C,D, respectively) organoids when exposed to $0.1,1,10$, and $30 \mu \mathrm{M}$ gefitinib for $24 \mathrm{~h}$ in black, $48 \mathrm{~h}$ in dark grey and $72 \mathrm{~h}$ in light grey, compared with Untreated controls. Values are in \% of luminescence. For each time point the average of Unt. Ctrl was set to $100 \%$. SD was calculated for each condition. Legend: Ctrl, control; SD, standard deviation; SI, small intestine; Unt, untreated; Veh, vehicle (with $0.1 \%$ DMSO). ${ }^{*} p$-value $=0.01 ;{ }^{* *} p$-value $=0.003$; ${ }^{* * *} p$-value $=0.0004 ;{ }^{* * *} p$-value $=0.0001$.

In the case of SI organoids (Figure 3C,D), no significant effect was found in either assay for the lower dose, except at $72 \mathrm{~h}$. At $1 \mu \mathrm{M}$, viability starts to decrease with concentration and time. Similar to the effects in colon organoids, the greatest decrease in viability was observed at the highest concentration and longer time points, declining by approximately $80 \%$ (Figure $3 \mathrm{C}$ ) In turn, there was no significant change in caspase activation until $30 \mu \mathrm{M}$ exposure, particularly at $48 \mathrm{~h}$ and $72 \mathrm{~h}$, which showed the largest increase in caspase activation (about $400 \%$ ) relative to the controls (Figure 3D).

\subsection{Evaluation of Morphological Changes by Image-Based Analysis}

Effects of gefitinib on the morphology and structure of the human organoids was evaluated, namely organoid size (growth inhibition), roundness (loss of bud-like differ- 
entiated structure) and percentage of cell death (cell cycle arrest and apoptosis activation) (Figure 4), nuclei size and number (growth/cell cycle inhibition). Size of the colon organoids (Figure 4A) did not change significantly upon exposure to gefitinib, whereas the size of SI organoids (Figure 4B) was significantly reduced in all treatment conditions, especially after $48 \mathrm{~h}$ and $72 \mathrm{~h}$ exposure. Moreover, SI organoids appeared more sensitive to changes in roundness with increases observed at $48 \mathrm{~h}$ with the lowest drug concentration, whereas colon organoid roundness only began to increase after exposure to $1 \mu \mathrm{M}$ and showed an overall lower degree of change (Figure 4C,D). As with the percentage of cell death, roundness was more significantly increased after exposure to $10 \mu \mathrm{M}$ for $72 \mathrm{~h}$ in both organoids (Figure 4E,F). However, this increase was more significant in colon than in SI organoids, particularly after exposure to the highest concentration at all time points, which is in line with the caspase $3 / 7$ activation described above.
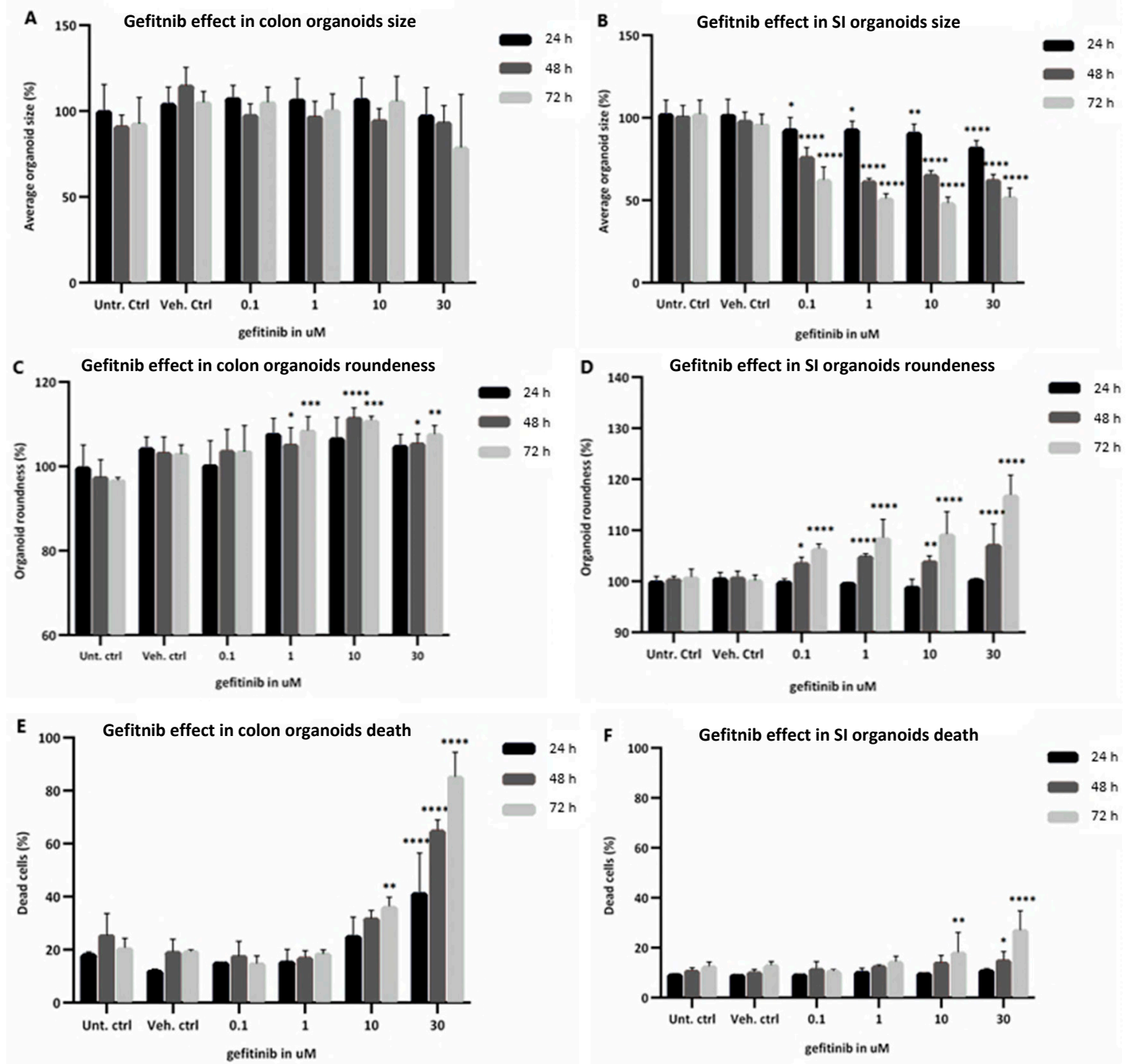

Figure 4. Morphological changes assessed through imaging analysis of healthy colon $(\mathrm{A}, \mathrm{C}, \mathrm{E})$ and SI (B,D,F) organoids when exposed to $0.1,1,10$ and $30 \mu \mathrm{M}$ gefitinib for $24 \mathrm{~h}$ in black, $48 \mathrm{~h}$ in light grey and $72 \mathrm{~h}$ in dark grey, compared with untreated controls. (A,B): organoid size; (C,D): organoid roundness; (E,F): percentage of dead cells. Values are in \% based on fluorescent intensity for each measured parameter. SD was calculated for each condition. Legend: Ctrl, control; SD, standard deviation; SI, small intestine; Unt, untreated; Veh, vehicle. ${ }^{*} p$-value $=0.01 ;{ }^{* *} p$-value $=0.008$; *** $p$-value $=0.0008 ; * * * *$-value $=0.0001$. 
In addition, exposure of colon organoids to gefitinib induced a modest time and concentration-dependent decrease of the nucleus size, with significant decreases in the number of nuclei per organoid at $48 \mathrm{~h}$ and $72 \mathrm{~h}$ (Figure S1A,C), which corresponds to an increase in cell death. In SI organoids, exposure to gefitinib led to a modest reduction of both nucleus size and number per organoid, being more significantly decreased at $30 \mu \mathrm{M}$ and $72 \mathrm{~h}$ (Figure S1B,D), indicating an induction of cell death at later time points. Furthermore, Figure S1E,F show microscope images of colon and SI organoids, comparing the morphological changes between the controls and gefitinib treatments.

In summary, the morphological changes reflected the results obtained for the viability and caspase 3/7 assays, as gefitinib inhibited cell growth in both organoids and led to cell death mainly in colon organoids in a time- and concentration-dependent manner. Size and roundness of SI organoids were in line with the decrease in viability, whereas in colon organoids only the increased roundness was in line with viability assay. This could suggest that colon organoids maintained their size throughout the exposure without growing further, rather than becoming smaller. The percentage of dead cells was also in line with the caspase activation assay, being more increased in colon than in SI organoids, thus suggesting activation of apoptotic events.

\section{4. mRNA Sequencing Data Processing and Pathway Analysis}

After the exposure of human colon and SI organoids to gefitinib, mRNA was isolated and sequenced. The obtained sequences were aligned with the human genome and ranged between $72.3 \%$ and $36.4 \%$ in colon samples and between $81.2 \%$ and $38.7 \%$ in SI samples. For normalization purposes, samples that yielded a number of read counts below 5 million were eliminated. As a result, 2 colon samples, from different treatment conditions, were not included in the analysis. All samples derived from SI organoids presented more than 5 million read counts. After applying the Bonferroni correction [30] and considering adjusted $p$ value $<0.05$, the number of DEGs tends to increase with gefitinib concentration and time of exposure. Furthermore, the number of DEGs was significantly higher in the colon organoids as compared to the SI in all treatment conditions, except for the lowest concentration $(0.1 \mu \mathrm{M})$.

After data processing, PCA score scatter plots were generated to observe how the treatment conditions with gefitinib would affect the samples derived from colon and SI and to further explore differences between gene expression of treated and untreated organoids (Figure 5). Looking at the colon organoids PCA plot (Figure 5A), Principal component 1 (PC1) was more correlated with the effect of concentration, and PC2, with the effect of time. It was observed that the controls were clustering together along with the lower concentration of gefitinib. There was also a clear separation between the different concentrations of gefitinib, although the two higher concentrations also clustered together on the right. Furthermore, this separation increased across time, as samples at $24 \mathrm{~h}$ and $48 \mathrm{~h}$ were closer and at $72 \mathrm{~h}$ there was a clearer separation. In the PCA plot obtained for SI organoids (Figure 5B), PC1 was also more correlated with the effect of concentration, and PC2 with the effect of time from $24 \mathrm{~h}$ to $48 \mathrm{~h}$ and $72 \mathrm{~h}$. There was a clear separation between $24 \mathrm{~h}$ and later time points. Moreover, $0.1 \mu \mathrm{M}$ was separated from the rest of the concentrations, particularly at $48 \mathrm{~h}$ and $72 \mathrm{~h}$, whereas higher concentrations appeared in a same cluster on the right and separation between them was more evident between $24 \mathrm{~h}$ and $48 \mathrm{~h} / 72 \mathrm{~h}$. Therefore, when comparing the distribution of samples from colon to SI organoids, in colon there was a clearer separation of samples in a concentration (PC1) and time (PC2) dependent manner. Similarly, in SI, the effect of concentration could be observed in PC1, whereas in PC2, there seemed to be an influence of time. 

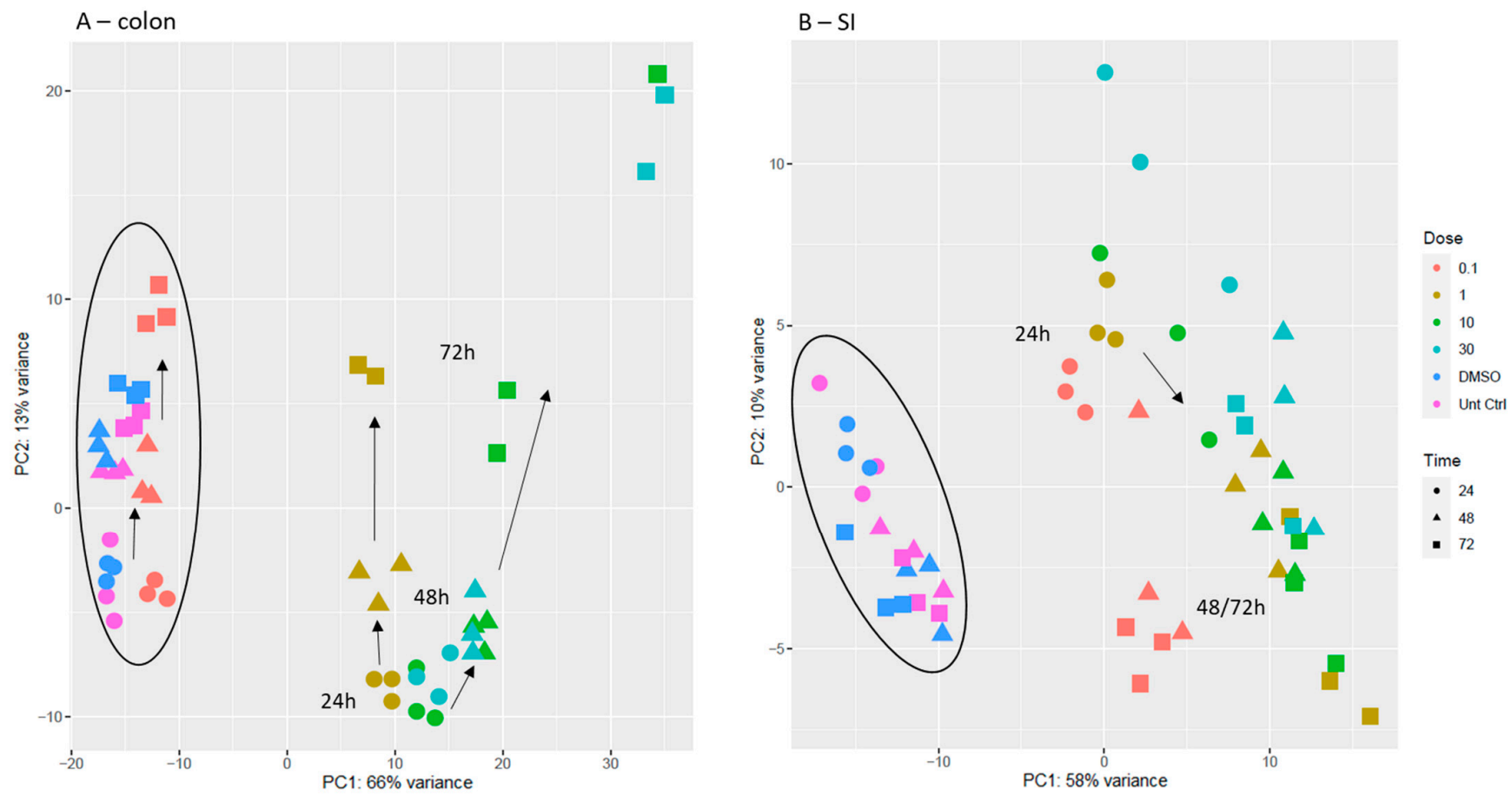

Figure 5. PCA score scatter plot obtained for the mRNA transcriptomic analysis of samples collected from colon organoids (A) and SI organoids (B). Direction of the arrows indicates the evolution in time of the samples ( $24 \mathrm{~h} \rightarrow 48 \mathrm{~h} \rightarrow 72 \mathrm{~h}$ ). In colon plot, cluster on the left comprises non-treated samples (untreated and vehicle controls); in SI plot, cluster on the left comprises non-treated samples and treated samples with $0.1 \mu \mathrm{M}$ gefitinib. Legend: untreated controls are in pink; vehicle controls (DMSO) are in dark blue; $0.1 \mu \mathrm{M}$ gefitinib in red; $1 \mu \mathrm{M}$ gefitinib in dark yellow; $10 \mu \mathrm{M}$ gefitinib in green; and $30 \mu \mathrm{M}$ gefitinib in light blue. Circles represent $24 \mathrm{~h}$; triangles, $48 \mathrm{~h}$; squares, $72 \mathrm{~h}$.

\subsection{Pathways and DEGs Affected by Gefitinib}

The effect of gefitinib on gene expression was observed in both organoids in a concentration- and time-dependent manner, particularly after exposure to $1 \mu \mathrm{M}$. The lowest concentration $(0.1 \mu \mathrm{M})$ did not significantly disturb the biological pathways and gene expression, in line with the results obtained in the cytotoxicity assays. The affected pathways and related DEGs were either on-target toxicity mechanisms (Table 2), i.e., modulated by gefitinib in an EGFR signalling inhibition dependent manner, or off-target (Table S2), i.e., not directly related to EGFR signalling inhibition but by other toxicity mechanisms triggered by gefitinib and its metabolites.

Table 2. Most relevant on-target pathways perturbed by gefitinib.

\begin{tabular}{|c|c|c|c|c|c|}
\hline \multirow{2}{*}{$\begin{array}{l}\text { Name of the } \\
\text { Pathway }\end{array}$} & \multirow{2}{*}{$\begin{array}{l}\text { Pathway } \\
\text { Source }\end{array}$} & \multirow{2}{*}{ Time (h) } & \multirow{2}{*}{$\begin{array}{c}\text { Gefitinib } \\
\text { Concentration }(\mu \mathrm{M})\end{array}$} & \multicolumn{2}{|c|}{ q-Value/Number of DEGs } \\
\hline & & & & Colon & SI \\
\hline \multirow{12}{*}{$\begin{array}{c}\text { EGF/EGFR } \\
\text { signalling pathway }\end{array}$} & \multirow{12}{*}{ Reactome } & \multirow{4}{*}{24} & 0.1 & $N A$ & $N A$ \\
\hline & & & 1 & $N A$ & $N A$ \\
\hline & & & 10 & $N A$ & $N A$ \\
\hline & & & 30 & $N A$ & $N A$ \\
\hline & & \multirow{4}{*}{48} & 0.1 & $N A$ & $N A$ \\
\hline & & & 1 & $N A$ & $N A$ \\
\hline & & & 10 & $N A$ & $N A$ \\
\hline & & & 30 & $N A$ & $N A$ \\
\hline & & \multirow{4}{*}{72} & 0.1 & $N A$ & $N A$ \\
\hline & & & 1 & $N A$ & $N A$ \\
\hline & & & 10 & $0.01 / 13$ & $N A$ \\
\hline & & & 30 & $0.01 / 17$ & $N A$ \\
\hline
\end{tabular}


Table 2. Cont.

\begin{tabular}{|c|c|c|c|c|c|}
\hline \multirow{2}{*}{$\begin{array}{c}\text { Name of the } \\
\text { Pathway }\end{array}$} & \multirow{2}{*}{$\begin{array}{l}\text { Pathway } \\
\text { Source }\end{array}$} & \multirow{2}{*}{ Time (h) } & \multirow{2}{*}{$\begin{array}{c}\text { Gefitinib } \\
\text { Concentration }(\mu \mathrm{M})\end{array}$} & \multicolumn{2}{|c|}{ q-Value/Number of DEGs } \\
\hline & & & & Colon & SI \\
\hline \multirow{12}{*}{$\begin{array}{c}\text { PI3K-Akt } \\
\text { signalling pathway }\end{array}$} & \multirow{12}{*}{ KEGG } & \multirow{4}{*}{24} & 0.1 & $0.04 / 2$ & $N A$ \\
\hline & & & 1 & $0.001 / 38$ & $0.04 / 11$ \\
\hline & & & 10 & $1.0 \times 10^{-4} / 48$ & $N A$ \\
\hline & & & 30 & $5.0 \times 10^{-4} / 51$ & $0.01 / 16$ \\
\hline & & \multirow{4}{*}{48} & 0.1 & $N A$ & $N A$ \\
\hline & & & 1 & $0.002 / 14$ & $0.13 / 14$ \\
\hline & & & 10 & $3.44 \times 10^{-5} / 55$ & $0.1 / 13$ \\
\hline & & & 30 & $4.98 \times 10^{-5} / 54$ & $N A$ \\
\hline & & \multirow{4}{*}{72} & 0.1 & $N A$ & $N A$ \\
\hline & & & 1 & $0.09 / 18$ & $0.05 / 23$ \\
\hline & & & 10 & $0.04 / 58$ & $N A$ \\
\hline & & & 30 & $0.08 / 82$ & $0.04 / 17$ \\
\hline \multirow{12}{*}{$\begin{array}{l}\text { MAPK signalling } \\
\text { pathway }\end{array}$} & \multirow{12}{*}{ Reactome } & \multirow{4}{*}{24} & 0.1 & $N A$ & $N A$ \\
\hline & & & 1 & $0.01 / 25$ & $0.02 / 10$ \\
\hline & & & 10 & $0.003 / 31$ & $N A$ \\
\hline & & & 30 & $0.01 / 32$ & $N A$ \\
\hline & & \multirow{5}{*}{48} & 0.1 & $N A$ & $N A$ \\
\hline & & & 1 & $0.14 / 20$ & $0.15 / 10$ \\
\hline & & & 10 & $0.03 / 31$ & $0.15 / 9$ \\
\hline & & & 30 & $0.04 / 29$ & $N A$ \\
\hline & & & 0.1 & $N A$ & $N A$ \\
\hline & & \multirow{3}{*}{72} & 1 & $N A$ & $0.08 / 16$ \\
\hline & & & 10 & $0.02 / 44$ & $N A$ \\
\hline & & & 30 & $0.04 / 60$ & $N A$ \\
\hline & & & 0.1 & $N A$ & $N A$ \\
\hline & & & 1 & $0.002 / 12$ & $0.14 / 3$ \\
\hline & & 24 & 10 & $0.003 / 13$ & $N A$ \\
\hline & & & 30 & $0.02 / 12$ & $N A$ \\
\hline & & & 0.1 & $N A$ & $N A$ \\
\hline Sionalling hy MFT & Reptom & & 1 & $0.002 / 12$ & $N A$ \\
\hline Signallıng by MET & Reactome & 48 & 10 & $0.004 / 14$ & $N A$ \\
\hline & & & 30 & $0.03 / 14$ & $N A$ \\
\hline & & & 0.1 & $N A$ & $N A$ \\
\hline & & & 1 & $0.02 / 7$ & $N A$ \\
\hline & & 72 & 10 & $4.0 \times 10^{-4} / 20$ & $N A$ \\
\hline & & & 30 & $1.22 \times 10^{-5} / 29$ & $N A$ \\
\hline & & & 0.1 & $N A$ & $0.06 / 4$ \\
\hline & & & 1 & $0.01 / 16$ & $0.005 / 8$ \\
\hline & & 24 & 10 & $0.003 / 20$ & $0.1 / 5$ \\
\hline & & & 30 & $0.005 / 21$ & $N A$ \\
\hline & & & 0.1 & $N A$ & $N A$ \\
\hline Signalling by & & & 1 & $N A$ & $0.06 / 8$ \\
\hline NOTCH & Reactome & 48 & 10 & $0.16 / 15$ & $N A$ \\
\hline & & & 30 & $0.09 / 16$ & $N A$ \\
\hline & & & 0.1 & $N A$ & $N A$ \\
\hline & & & 1 & $0.06 / 9$ & $N A$ \\
\hline & & 72 & 10 & $0.005 / 28$ & $N A$ \\
\hline & & & 30 & $1.28 \times 10^{-5} / 46$ & $N A$ \\
\hline & & & 0.1 & $N A$ & $N A$ \\
\hline & & & 1 & $0.04 / 15$ & $N A$ \\
\hline & & 24 & 10 & $0.01 / 19$ & $N A$ \\
\hline & & & 30 & $0.06 / 18$ & $0.0003 / 12$ \\
\hline & & & 0.1 & $N A$ & $N A$ \\
\hline FOXO-mediated & & & 1 & $N A$ & $0.07 / 8$ \\
\hline transcription & Reactome & 48 & 10 & $0.12 / 17$ & $0.003 / 10$ \\
\hline & & & 30 & $N A$ & $0.02 / 10$ \\
\hline & & & 0.1 & $N A$ & $N A$ \\
\hline & & & 1 & $N A$ & $0.007 / 14$ \\
\hline & & 72 & 10 & $N A$ & $0.002 / 12$ \\
\hline & & & 30 & $0.05 / 36$ & $0.04 / 9$ \\
\hline
\end{tabular}


Table 2. Cont.

\begin{tabular}{|c|c|c|c|c|c|}
\hline \multirow{2}{*}{$\begin{array}{l}\text { Name of the } \\
\text { Pathway }\end{array}$} & \multirow{2}{*}{$\begin{array}{l}\text { Pathway } \\
\text { Source }\end{array}$} & \multirow{2}{*}{ Time (h) } & \multirow{2}{*}{$\begin{array}{c}\text { Gefitinib } \\
\text { Concentration }(\mu \mathrm{M})\end{array}$} & \multicolumn{2}{|c|}{ q-Value/Number of DEGs } \\
\hline & & & & Colon & SI \\
\hline \multirow{12}{*}{$\begin{array}{l}\text { p53 signalling } \\
\text { pathway }\end{array}$} & \multirow{12}{*}{ KEGG } & \multirow{4}{*}{24} & 0.1 & $N A$ & $N A$ \\
\hline & & & 1 & $0.009 / 12$ & $N A$ \\
\hline & & & 10 & $0.02 / 12$ & $N A$ \\
\hline & & & 30 & $0.06 / 12$ & $0.0003 / 9$ \\
\hline & & \multirow{4}{*}{48} & 0.1 & $N A$ & $N A$ \\
\hline & & & 1 & $0.09 / 9$ & $0.06 / 6$ \\
\hline & & & 10 & $0.02 / 14$ & $N A$ \\
\hline & & & 30 & $0.06 / 12$ & $0.0005 / 10$ \\
\hline & & \multirow{4}{*}{72} & 0.1 & $N A$ & $N A$ \\
\hline & & & 1 & $N A$ & $0.02 / 9$ \\
\hline & & & 10 & $N A$ & $0.001 / 9$ \\
\hline & & & 30 & $N A$ & $0.001 / 9$ \\
\hline \multirow{12}{*}{$\begin{array}{l}\text { Regulation of } \\
\text { mitotic cell cycle }\end{array}$} & \multirow{12}{*}{ Reactome } & \multirow{4}{*}{24} & 0.1 & $N A$ & $N A$ \\
\hline & & & 1 & $0.01 / 8$ & $N A$ \\
\hline & & & 10 & $0.001 / 11$ & $N A$ \\
\hline & & & 30 & $0.003 / 11$ & $0.04 / 4$ \\
\hline & & \multirow{5}{*}{48} & 0.1 & $N A$ & $N A$ \\
\hline & & & 1 & $N A$ & $N A$ \\
\hline & & & 10 & $N A$ & $N A$ \\
\hline & & & 30 & $N A$ & $N A$ \\
\hline & & & 0.1 & $0.01 / 2$ & $N A$ \\
\hline & & \multirow{3}{*}{72} & 1 & $N A$ & $N A$ \\
\hline & & & 10 & $0.13 / 9$ & $N A$ \\
\hline & & & 30 & $0.09 / 13$ & $N A$ \\
\hline \multirow{12}{*}{ Cellular senescence } & \multirow{12}{*}{ KEGG } & \multirow{4}{*}{24} & 0.1 & $N A$ & $N A$ \\
\hline & & & 1 & $0.01 / 19$ & $N A$ \\
\hline & & & 10 & $0.06 / 16$ & $N A$ \\
\hline & & & 30 & $0.004 / 26$ & $0.01 / 10$ \\
\hline & & \multirow{4}{*}{48} & 0.1 & $N A$ & $N A$ \\
\hline & & & 1 & $0.012 / 15$ & $N A$ \\
\hline & & & 10 & $0.05 / 22$ & $N A$ \\
\hline & & & 30 & $0.01 / 24$ & $0.003 / 13$ \\
\hline & & \multirow{4}{*}{72} & 0.1 & $N A$ & $N A$ \\
\hline & & & 1 & $N A$ & $0.002 / 17$ \\
\hline & & & 10 & $N A$ & $3.0 \times 10^{-4} / 15$ \\
\hline & & & 30 & $0.14 / 39$ & $3.0 \times 10^{-4} / 15$ \\
\hline \multirow{12}{*}{ Apoptosis } & & & 0.1 & $N A$ & $N A$ \\
\hline & & & 1 & $N A$ & $N A$ \\
\hline & & 24 & 10 & $0.11 / 14$ & $N A$ \\
\hline & & & 30 & $N A$ & $N A$ \\
\hline & & & 0.1 & $N A$ & $N A$ \\
\hline & & & 1 & $N A$ & $0.09 / 7$ \\
\hline & Reactome & 48 & 10 & $0.15 / 15$ & $N A$ \\
\hline & & & 30 & $0.13 / 15$ & $N A$ \\
\hline & & & 0.1 & $N A$ & $N A$ \\
\hline & & & 1 & $N A$ & $0.008 / 13$ \\
\hline & & 72 & 10 & $0.06 / 23$ & $N A$ \\
\hline & & & 30 & $0.05 / 33$ & $0.02 / 9$ \\
\hline
\end{tabular}

Legend: significant q-values < 0.05 (in bold) or not applicable (NA) when the respective pathways were not present; KEGG, Kyoto Encyclopaedia of Genes and Genomes.

\subsubsection{Signalling Transduction Pathways}

The biological processes that stood out as significantly affected were signalling transduction pathways triggered by the EGFR, including EGF/EGFR, PI3K-Akt and MAPK signalling cascades, signalling by MET and signalling by NOTCH (Table 2), which are in line with the known mechanism of action of the drug (i.e., EGFR inhibition) [2]. In the colon these pathways were more affected than in SI since overall q-values were lower and the number of DEGs involved were higher for colon organoids. In view of the fact that the activity of these signalling pathways is dependent on phosphorylations and that mRNA sequencing data does not provide information on protein level changes, we next looked into the DEGs whose expression depends on those signalling cascades and pathways in which the DEGs are involved, using Reactome, Kyoto Encyclopaedia of Genes and Genomes (KEGG) and WikiPathways as references (Table 3). 
Table 3. Expression changes of the DEGs affected by gefitinib in colon and SI organoids.

\begin{tabular}{|c|c|c|c|}
\hline Gene Symbol & Pathways Involved/Function & $\begin{array}{l}\text { Expression in Treated Colon/SI } \\
\text { Cells (Adjusted } p \text {-Value) }\end{array}$ & Remarks \\
\hline \multicolumn{4}{|c|}{ DEGs with same trend in colon and SI organoids } \\
\hline AREG & $\begin{array}{l}\text { Interaction with EGFR to promote growth of } \\
\text { epithelial cells }\end{array}$ & $\downarrow\left(9.7 \times 10^{-8}\right) / \downarrow\left(6.5 \times 10^{-7}\right)$ & \\
\hline AURKA & DNA repair; Cell cycle & $\downarrow\left(3.9 \times 10^{-6}\right) / \downarrow(0.04)$ & \\
\hline$B A X$ & Induction of apoptosis & $\uparrow\left(1.5 \times 10^{-4}\right) / \uparrow(1.0)$ & $\begin{array}{l}\text { Activated in gefitinib treated } \\
\text { gallbladder cancer cells [31] }\end{array}$ \\
\hline BCL2L11 (BIM) & Induction of apoptosis & $\uparrow\left(2.1 \times 10^{-5}\right) / \uparrow\left(1.1 \times 10^{-8}\right)$ & $\begin{array}{l}\uparrow \text { linked to higher sensitivity to } \\
\text { gefitinib in NSCLC [32] }\end{array}$ \\
\hline BTG2 & Cell cycle arrest (G1/S) & $\uparrow\left(5.5 \times 10^{-29}\right) / \uparrow\left(7.1 \times 10^{-6}\right)$ & \\
\hline$c-M Y C$ & Cell cycle progression & $\downarrow\left(8.1 \times 10^{-30}\right) / \downarrow\left(1.7 \times 10^{-10}\right)$ & \\
\hline CCND1 & Cell cycle/proliferation & $\downarrow(0.03) / \downarrow\left(2.8 \times 10^{-32}\right)$ & $\downarrow$ in gefitinib treated IEC [33] \\
\hline CCNG1 & Cell cycle arrest & $\downarrow\left(5.5 \times 10^{-6}\right) / \downarrow(1.0)$ & \\
\hline CCNG2 & Cell cycle arrest & $\uparrow(1.0) / \uparrow(0.004)$ & \\
\hline CDH1 & E-cadherin; cell adhesion molecule & $\downarrow\left(8.5 \times 10^{-8}\right) / \downarrow\left(1.5 \times 10^{-5}\right)$ & $\downarrow$ in TKI-treated IEC $[33,34]$ \\
\hline DDB2 & DNA repair & $\uparrow(0.13) / \uparrow\left(1.4 \times 10^{-4}\right)$ & \\
\hline FGF19 & $\begin{array}{l}\text { Cell growth, tissue repair, effects on glucose } \\
\text { and lipid metabolism }\end{array}$ & $\downarrow\left(9.6 \times 10^{-9}\right) / \downarrow(0.02)$ & $\downarrow$ in chronic diarrhoea [35] \\
\hline ITGB1 & $\begin{array}{l}\text { } \beta 1 \text {-integrin; cell adhesion, embryogenesis, } \\
\text { homeostasis, tissue repair, immune response }\end{array}$ & $\downarrow\left(8.3 \times 10^{-17}\right) / \downarrow(1.0)$ & $\downarrow$ in TKI-treated IEC [34] \\
\hline MUC20 & Suppressor of MET signalling/proliferation & $\uparrow\left(9.0 \times 10^{-9}\right) / \uparrow(0.005)$ & \\
\hline MYBL2 & Cell cycle/proliferation & $\downarrow(1.0) / \downarrow\left(6.1 \times 10^{-4}\right)$ & \\
\hline PCNA & DNA repair & $\uparrow\left(1.4 \times 10^{-8}\right) / \uparrow(1.0)$ & \\
\hline PERP & $\begin{array}{l}\text { Apoptosis effector; epithelial integrity and } \\
\text { cell-cell adhesion }\end{array}$ & $\downarrow\left(1.7 \times 10^{-16}\right) / \downarrow(0.03)$ & \\
\hline SFN & Cell cycle arrest (G2/M) & $\downarrow\left(1.1 \times 10^{-7}\right) / \downarrow(0.04)$ & \\
\hline SUSD6 (KIAA0247) & $\begin{array}{l}\text { Suppressor of cell growth; activator of } \\
\text { apoptosis }\end{array}$ & $\uparrow\left(8.8 \times 10^{-6}\right) / \uparrow(1.0)$ & \\
\hline TLR2 & Inflammatory signals & $\uparrow(0.005) / \uparrow(1.0)$ & \\
\hline TNFRSF10 (TRAIL-R2) & Induction of apoptosis & $\downarrow(0.007) / \downarrow(1.0)$ & \\
\hline TNS3 & Cell motility/migration & $\uparrow\left(6.5 \times 10^{-14}\right) / \uparrow(1.0)$ & \\
\hline TNS4 & Cell motility/migration & $\downarrow(0.01) / \downarrow\left(5.8 \times 10^{-8}\right)$ & \\
\hline \multicolumn{4}{|c|}{ DEGs with opposite trend in colon and SI organoids } \\
\hline$A B C A 1$ & Efflux of cholesterol & $\uparrow(0.02) / \downarrow(1.0)$ & \\
\hline$c-F O S$ & Cell cycle progression & $\downarrow\left(3.2 \times 10^{-6}\right) / \uparrow(1.0)$ & \\
\hline CYP51A1 & Cholesterol biosynthesis & $\downarrow\left(1.4 \times 10^{-22}\right) / \uparrow\left(2.2 \times 10^{-8}\right)$ & \\
\hline DTX3 & Regulator of Notch signalling & $\uparrow(0.03) / \downarrow(1.0)$ & \\
\hline FUCA1 & $\begin{array}{l}\text { Degradation of glycoproteins and } \\
\text { glycolipids }\end{array}$ & $\downarrow\left(8.7 \times 10^{-7}\right) / \uparrow(1.0)$ & \\
\hline HMGCR & Cholesterol biosynthesis & $\downarrow\left(4.5 \times 10^{-11}\right) / \uparrow\left(7.4 \times 10^{-4}\right)$ & \\
\hline HMGCS1 & Cholesterol biosynthesis & $\downarrow\left(1.6 \times 10^{-4}\right) / \uparrow(0.004)$ & \\
\hline РЕРСК & Glucose metabolism & $\downarrow\left(3.1 \times 10^{-6}\right) / \uparrow(1.0)$ & \\
\hline
\end{tabular}


Table 3. Cont.

\begin{tabular}{ccc}
\hline Gene Symbol & Pathways Involved/Function & $\begin{array}{c}\text { Expression in Treated Colon/SI } \\
\text { Cells (Adjusted } \boldsymbol{p} \text {-Value) }\end{array}$ \\
\hline PRKAB1 & AMPK-mediated metabolism & $\uparrow\left(7.9 \times 10^{-10}\right) / \downarrow(0.008)$ \\
\hline SESN1 & DNA damage and oxidative stress response; & $\uparrow\left(1.4 \times 10^{-7}\right) / \downarrow(1.0)$ \\
\hline
\end{tabular}

Legend: * adjusted $p$-values (in brackets) above 0.05 were considered as not significant; $\uparrow-$ upregulated; $\downarrow$-downregulated; IEC —-intestinal epithelial cells; NSCLC—non-small cell lung cancer.

Starting with the DEGs regulated by the EGFR pathway, the majority of genes found to be significantly affected are involved in cell cycle progression (phase G1/S) and proliferation, namely AURKA (also important in DNA repair), CCND1 (cyclin D1), c-MYC, c-FOS and MYBL2, with the only exception of BCL2L11, which is involved in regulation of apoptosis, being mostly pro-apoptotic. Additional genes PEPCK (glucose metabolism) and CCNG2 (cell cycle arrest), were also found to be significantly affected. These two genes are regulated by FOXO-mediated signalling, which is closely related to EGFR activity. Expression levels of AURKA were decreased in colon at $24 \mathrm{~h}$, whereas in SI, only after $72 \mathrm{~h}$ exposure to $30 \mu \mathrm{M}$. CCND1 and $c-M Y C$ presented similar profile changes, being more downregulated at $24 \mathrm{~h}$ in colon and after $48 \mathrm{~h}$ exposure in SI. Expression levels of $c$-FOS and PEPCK were only found significantly changed in the colon, the first being decreased in all treatment conditions and more at $24 \mathrm{~h}$, and the second being decreased only after $48 \mathrm{~h}$ and $72 \mathrm{~h}$ exposure to 10 and $30 \mu \mathrm{M}$. On the other hand, MYBL2 and CCNG2 were only observed in SI. Expression levels of MYBL2 tended to decrease across treatment conditions with the largest decrease at $24 \mathrm{~h}, 30 \mu \mathrm{M}$, while expression levels of CCNG2 tended to increase, being more upregulated at $72 \mathrm{~h}$. In turn, pro-apoptotic gene BCL2L11 was found upregulated in both organoids. Expression levels of this gene were more increased at $24 \mathrm{~h}$ in colon, whereas in SI they did not change much throughout the exposure.

Furthermore, PI3K signalling related gene AREG (cell growth) was found downregulated in both organoids, but more in the colon. Expression levels of FGF19, which is involved in several cellular processes (growth, tissue repair, and metabolism) tended to decrease across concentration and time in colon, and in SI, they were decreased only at $1 \mu \mathrm{M}$, all time points, and $10 \mu \mathrm{M}, 24 \mathrm{~h}$. Another interesting gene, MUC20 (suppressor of signalling by MET), was found upregulated in both organoids but in different treatment conditions. In colon, MUC20 was only upregulated after $72 \mathrm{~h}$ exposure to 10 and $30 \mu \mathrm{M}$, and in SI after exposure to $1 \mu \mathrm{M}$ for $24 \mathrm{~h}$ and $48 \mathrm{~h}$. In colon organoids, two other genes associated with signalling pathways were significantly upregulated, namely TLR2 (inflammation signals) and DTX3 (signalling by NOTCH) whereas, in SI organoids, they were not significantly affected by the drug.

\subsection{2. p53 Signalling Pathway}

Additionally, p53 signalling pathway, which regulates gene expression during stress conditions [36], was also significantly affected, presenting lower q-values for SI organoids but only significant after $72 \mathrm{~h}$ exposure to $1 \mu \mathrm{M}$, whereas in the colon q-values decreased after $24 \mathrm{~h}$ exposure to $1 \mu \mathrm{M}$ (Table 1 ). More DEGs were significantly affected by the p53 signalling pathway in the colon upon exposure to gefitinib, all of which being involved in either gefitinib on-target processes, namely cell cycle arrest, cell growth, DNA repair, and apoptosis (Table 3), and off-target processes such as metabolism (Table S2). Starting with genes in common between colon and SI organoids, cell cycle arrest genes BTG2 (G1/S phase) and SFN (G2/M phase) were found upregulated and downregulated, respectively, for all treatment conditions, but more significantly in colon. Apoptotic gene PERP was significantly downregulated after $72 \mathrm{~h}$ exposure, especially in colon for the higher concentrations. The gene PRKAB1, an encoding gene of the regulatory subunit of the activated protein kinase (AMPK), was upregulated in colon after $72 \mathrm{~h}$ exposure whereas in SI, it was downregulated. Additionally, in colon organoids, the PCNA (DNA repair), SUSD6 
and BAX (apoptosis), and SESN1 (response to DNA damage and oxidative stress) genes were significantly upregulated, at different treatment conditions. In turn, the CCNG1 (cell cycle), TNFRSF10 (apoptosis) and FUCA1 (metabolism of glycoproteins and glycolipids) genes were significantly downregulated after $72 \mathrm{~h}$ exposure to $30 \mu \mathrm{M}$. Only one gene was significantly changed in SI but not in colon, namely DDB2 (DNA repair), being only upregulated after $48 \mathrm{~h}$ exposure to $30 \mu \mathrm{M}$.

\subsubsection{Cell Cycle and Cellular Senescence}

In addition to signalling transduction pathways, other important gefitinib on-target cellular processes were investigated to further understand gefitinib effects on the organoids. Firstly, cell cycle was not significantly affected overall, as well as DNA synthesis/replication, except for regulation of mitotic cell cycle at $24 \mathrm{~h}$ (Table 2). This was more evident in colon (lower q-values) as also more genes had their levels decreased upon exposure. In contrast, mechanisms of cell cycle arrest prevailed with CCND1 and $c-M Y C$ downregulated as described above but expression levels of cell cycle inhibitors p27 and p21 were not found significantly affected in both organoids. However, cellular senescence, which consists of an irreversible cell cycle arrest, was affected in both organoids, but particularly earlier in colon than in SI. Induction of apoptosis was not significantly modulated by the exposure until later treatment conditions in both organoids, in which q-values were lower in SI (Table 2). Nevertheless, expression levels of pro-apoptotic genes BCL2L11, BAX, TNFSF10, PERP and SUSD6 were more significantly increased in colon. Likewise, anti-apoptotic genes BCL2L1, MCL1 and BIRC3 were more significantly downregulated in colon.

\subsubsection{Cell Motility and Adhesion}

We next looked into expression of genes associated with cell motility and adhesion since levels of cell adhesion molecules, namely E-cadherin, $\beta 1$-integrin and ZO-1, were reported as significantly inhibited in previous studies $[33,34]$. In our study, the genes encoding for E-cadherin (CDH1) and $\beta 1$-integrin (ITGB1) were significantly downregulated, the first in both organoids and the second only in colon organoids (Table 3). Levels of ZO-1 encoding gene TJP1 were not significantly affected. In addition, genes TNS3 and TNS4, involved in signal transduction pathways for cell motility/migration and whose expression is regulated by EGFR activity, were found upregulated and downregulated, respectively. Under normal circumstances, EFG activates TNS4 and inhibits TNS3, so exposure to gefitinib reversed their expression profile.

\subsubsection{Immune Responses}

The increase in the expression of the pro-inflammatory cytokines interleukin (IL)- 6 and IL-25 has been reported [33]. In our study, IL-6, IL-1 and IFN- $\gamma$ signalling pathways were also significantly affected in colon organoids at 72 h, 10 and $30 \mu \mathrm{M}$ based on q-values. Despite that, expression levels of cytokines were not significantly affected except for IL-1, which was found downregulated. In SI organoids, immune responses and expression levels of cytokines were not found significantly changed.

In summary, the results show that gefitinib on-target toxicity signalling transduction pathways, namely EGFR, PI3K, MET and NOTCH signalling, were significantly affected, which consequently affected the expression of genes directly regulated by these signalling cascades including AURKA, CCND1, c-MYC, c-FOS and FGF19 (Table 3). Most of these genes were downregulated over time and concentrations of gefitinib, except $c-F O S$ in the SI organoids. Regarding expression of p53 gene, it was not significantly changed but DEGs influenced by p53 signalling pathways, as well as on-target toxicity mechanisms, were affected across treatment conditions, namely cell cycle arrest-related genes BTG2 and CCNG1 (upregulated), and CCNG1 and SFN (downregulated), apoptotic genes BAX, BCL2L11 and SUSD6 (upregulated), PERP and TNFRSF10 (downregulated), and impairment of cell growth and DNA repair-related genes DDB2, PCNA and SESN1 (upregulated). Gefitinib on-target DEGs involved in cell adhesion and motility (E-cadherin, $\beta 1$-integrin 
and TNS4) were significantly downregulated across treatment conditions, which reflects additional damaging effects caused by gefitinib. Therefore, expression levels of the genes listed above (Table 3) and represented in Figure 6 were in line with the anti-proliferative effects of the drug, cell cycle arrest, DNA repair, and cell motility/migration. Immune signalling pathways and levels of pro-inflammatory cytokines, an off-target toxicity mechanism, were only significantly modulated in colon. Furthermore, results also indicate that even though similar mechanisms are perturbed by gefitinib in colon and SI cells, genes and their expression levels are distinct.
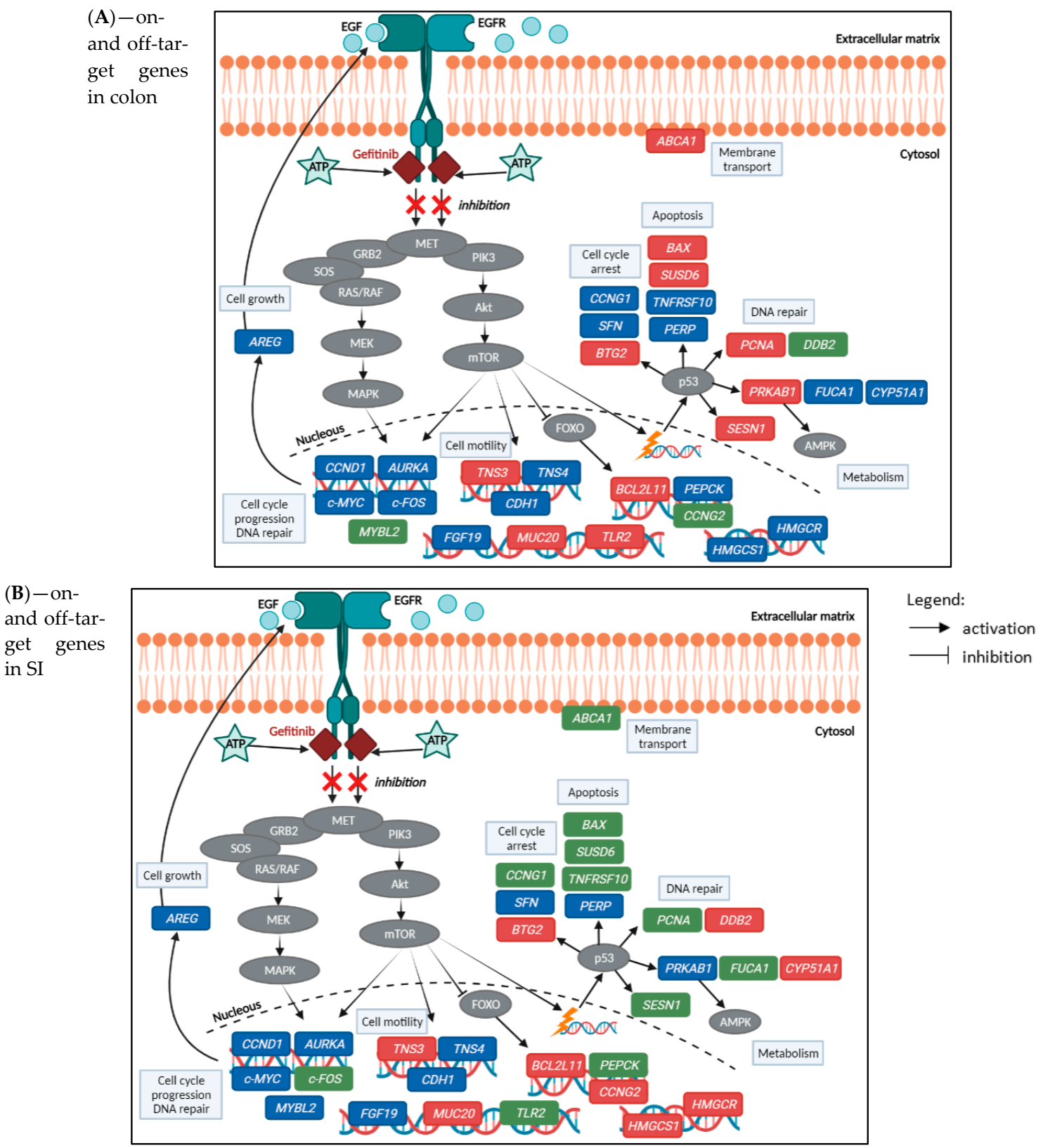

Figure 6. Representation of gefitinib effects on expression levels of on- and off-target genes in the colon (A) and SI (B) organoids, elucidating the drug's potential mechanisms of toxicity. For the alterations in the gene expression levels, all treatment conditions were considered. Legend: genes in blue-significantly downregulated; red-significantly upregulated, after Bonferroni correction (adjusted $p$-value < 0.05 ); green—not available/not significant; grey-protein expression not available. Image created with BioRender.com (accessed on 26 June 2021). 


\subsubsection{Metabolic Pathways and Cholesterol Biosynthesis}

Metabolism is considered as an off-target toxicity mechanism induced by gefitinib and was significantly affected in both organoids. The effect was stronger in colon than in SI (Table S2) and at different treatment conditions. One exception was drug metabolism by cytochrome P450, which was more relevant for SI organoids throughout all treatment conditions, with q-values lower than those observed for colon. This could indicate a novel finding on a tissue-specific response to the drug by SI organoids. Indeed, looking at the expression of the CYP450 genes involved in gefitinib metabolism, CYP3A4 was only found significantly downregulated in colon $\left(p\right.$-value $\left.=5.1 \times 10^{-16}\right)$ whereas CYP3A5 was only found significantly upregulated in SI ( $p$-value $\left.=3.9 \times 10^{-30}\right)$.

Metabolism of proteins and amino acids were similarly affected, with q-values decreasing across concentrations, at earlier treatment conditions in SI (48) than in colon organoids (72 h). Key metabolic pathways for energy production, including glycolysis, TCA cycle, pyruvate metabolism, respiratory electron chain and ATP synthesis, and metabolism of lipids, were observed and q-values were overall lower for colon organoids and more significant at earlier treatment conditions than for SI (Table S2). TCA cycle and ATP synthesis were not significantly affected in SI organoids. Expression levels of DEGs involved in these energy generation pathways were decreased in both organoids, except for DEGs involved in metabolism of lipids. Interestingly, lipogenesis related genes were downregulated in colon but upregulated in SI organoids. Likewise, cholesterol biosynthesis was differently affected in colon and SI. While this pathway was affected in colon organoids after $1 \mu \mathrm{M}$ exposure and q-values tended to increase across concentrations, in SI q-values were only significantly increased after exposure to $30 \mu \mathrm{M}$. DEGs involved in cholesterol biosynthesis also presented opposite direction of expression, thus downregulated in colon and upregulated in SI organoids (Figure S2).

Next, we looked into possible differences related to the endoplasmic reticulum (ER) stress responses and key regulatory genes of metabolic balance that could aid in understanding the distinct expression of DEGs involved in cholesterol biosynthesis. First, we checked the expression levels of SREBP1 since the pathway "regulation of cholesterol biosynthesis by SREBP" was as significantly affected as cholesterol biosynthesis (similar q-values). This gene regulates transcription of key enzymes that participate in cholesterol biosynthesis namely HMG-CoA synthase (HMGCS1) and HMG-CoA reductase (HMGCR). Nevertheless, expression of SREBP was not conclusive as it was found upregulated in colon and not significantly affected in SI. Nevertheless, as shown in Figure S2, the encoding genes HMGCS1 and HMGCR were downregulated in colon and upregulated in SI after the exposure. Next, we investigated if ER stress could have impacted cholesterol biosynthesis, as reported previously [33], but pathway and gene expression analysis showed that gefitinib did not induce ER stress in the organoids.

We also evaluated the expression of PRKAB1, which regulates metabolism via AMPK, depending on p53 signalling activity. The PRKAB1 gene was found upregulated in colon and downregulated in SI. This could indicate that AMPK became activated in colon unlike in SI, which could explain the differences in the metabolic responses upon TKI-induced stress, namely the contrast in the cholesterol de novo synthesis and metabolism of lipids. Further differences between colon and SI organoids were the expression levels of genes encoding CYP51A1 and ABCA1. The first is a crucial enzyme in cholesterol biosynthesis and expression levels were decreased in colon and increased in SI. In contrast, $A B C A 1$, a membrane transporter responsible for cholesterol efflux in the form of HDL, was upregulated in colon organoids only. These metabolic genes are also indicated in Table 3.

Taken all together, gefitinib off-target metabolic processes were differently affected in both organoid types. Drug metabolism prevailed in SI as CYP3A5 was upregulated across treatment conditions whereas, whereas CYP3A4 was downregulated in colon. Energy production pathways were more significantly affected in colon, involving TCA cycle and ATP synthesis exclusively in these organoids. DEGs involved in these pathways were downregulated over time and concentrations except genes involved in the metabolism of 
lipids and cholesterol biosynthesis, as these were upregulated in SI in contrast to colon. These novel and promising observations emphasize the different responses of colon and SI organoids to gefitinib. Figure 6 also provides an overview of the effects of gefitinib in the expression of key genes involved in metabolism, namely in cholesterol biosynthesis, highlighting the differences between colon and SI organoids.

\section{Discussion}

Oral TKIs including gefitinib are becoming more common in the treatment of some cancers, such as NSCLC, renal cell carcinoma, metastatic breast cancer or colorectal cancer [37]. However, the side effects that this class of drugs may cause, particularly intestinal damage and diarrhoea [10], have been underestimated and are mechanistically not fully understood.

In this study, we investigated the molecular mechanisms underlying the toxic effects of gefitinib in a newly established 3D culture of healthy human intestinal organoids derived from colon and SI tissues. These in vitro models have been developed to better resemble the characteristics and responses of the human tissues [18,38,39] and they have been successfully applied in the research of drug toxicity induced by 5-FU [14] and doxorubicin [40]. PBPK modelling was used in order to determine in-vitro drug concentrations that are clinically relevant. Overall, the cytotoxicity and transcriptomic data corroborates the gefitinib inhibitory effect on EGFR kinase signalling pathways and on intestinal cells growth. EGFR-regulated genes ( $A U R K A, C C N D 1, c-M Y C, c-F O S$ and FGF19) were downregulated, hampering cell cycle progression and cell differentiation, in line with the decreased cell viability and increased organoid roundness reflecting reduced differentiation of the organoids. Adhesion-related genes were downregulated as previously reported [33,34]. Furthermore, p53 and FOXO-regulated genes involved in cell cycle arrest and pro-apoptotic processes were upregulated, whereas anti-apoptotic genes were downregulated, particularly in colon organoids, which also presented a higher percentage of dead cells than SI. Novel and promising findings were metabolism related, showing more organ specific responses. Drug metabolism prevailed in SI with upregulation of CYP3A5, whereas in colon it was downregulated. Additionally, metabolism of lipids and cholesterol biosynthesis-related genes showed opposite direction of expression in colon and SI organoids after the exposure. These findings emphasize tissue-specific responses as colon seems to be more sensitive to the drug effects and SI seems to be more resistant. These gefitinib-induced gene expression changes are highlighted in Figure 6.

As mentioned previously, the known on-target mechanism of action for gefitinib is the selective blockade of EGFR-tyrosine kinase domain, preventing ATP from binding to it. As a result, EGFR autophosphorylation is inhibited as well as the activation of the signalling cascades associated with the receptor that would promote cell proliferation, growth and inhibition of apoptosis [3] (Figure 6). In our study, we observed the anti-proliferative ad apoptotic effects of gefitinib on the intestinal organoids, starting with the cytotoxicity assays and morphological changes. Gefitinib caused a decrease in cell viability and induction of apoptosis in both organoids, in a concentration- and time-dependent manner. Differences in the cytotoxicity results between the organoids were reflected in the viability being decreased already for the lowest dose, at $72 \mathrm{~h}$, in SI organoids, but caspase 3/7 activation being increased more significantly and earlier in colon organoids (Figure 3). Likewise, image-based analysis (Figure 4) showed the drug effect on size and shape, which were more significantly perturbed in SI organoids, whereas percentage of cell death was more noticeable in colon organoids after exposure to $30 \mu \mathrm{M}$. The observations in the caspase activation assay were in line with the percentage of cell death. Nevertheless, pathway analysis showed that induction of apoptosis was not significantly affected throughout the treatment conditions.

Pathway analysis on genes that were differentially expressed after exposure showed that on-target signalling transduction cascades and gene expression regulators p53 and FOXO were affected by gefitinib, being the first to be more significantly affected in colon, and p53 and FOXO signalling pathways more affected in SI organoids (Table 2). Down- 
stream genes regulated by these signalling cascades and involved in cell cycle progression, cell growth and proliferation were downregulated, including CCND1, c-MYC, AURKA, AREG, FGF19, and tissue-specific c-FOS and MYBL2 (Table 2). Cyclin D1 (CCND1) and p27 have been reported as downregulated in a previous study with gefitinib-treated IEC [33]. In our study, neither p27 nor p21 were found as modulated genes, which could indicate that healthy intestinal organoids are sensitive to gefitinib through a mechanism dependent on Cyclin D1, c-MYC and p53 rather than p27/p21. In fact, similar findings were reported in a study with colon cancer cell lines HCT116 treated with TKIs [41]. Furthermore, increased expression of $A R E G$ and $A U R K A$ in lung cancer cells has been associated with resistance to gefitinib treatment $[42,43]$. Remarkably, FGF19 was found downregulated in cases of chronic diarrhoea caused by bile acid malabsorption [35], thus this gene could be an indicator of increased risk of diarrhoea in cancer patients taking gefitinib. Furthermore, DNA repair and damage/oxidative stress response genes PCNA and SESN1, in colon, and $D D B 2$, in SI, were upregulated, which can represent a response of the organoids against the damaging effects of the drug. In contrast, downstream genes involved in cell cycle arrest, supressing proliferation, and activation of apoptosis were mostly upregulated. This relates to BCL2L11, BTG2, MUC20, and tissue-specific response genes BAX, CCNG2 and SUSD6 (Table 3). In previous studies, overexpression of BCL2L11 and BAX have been associated with higher sensitivity of cancer cells to gefitinib [31,32].

Gefitinib also decreased the expression of adhesion molecules E-cadherin and $\beta 1$-integrin, even though the effect on $\beta 1$-integrin was only observed in colon organoids. Likewise, two previous studies on gefitinib and other TKIs corroborate these findings [33,34]. Levels of PERP, important in the maintenance of epithelial integrity and cell-cell adhesion, were decreased by gefitinib, which could aggravate the damaging effects of the drug. Moreover, the balance of the levels of TNS3 and TNS4 was disrupted by gefitinib effects on EGFR, hindering cell motility/migration.

Gefitinib off-target immune responses were significantly affected in colon organoids (Table 3), particularly IL-6, IL-1 and IFN- $\gamma$ signalling pathways at later treatment conditions. However, gene expression levels of IL6, IL25 and IFNG were not significantly changed, whereas IL1 was downregulated, which is in contrast with previous studies [33,34]. In addition, levels of toll-like receptor encoding gene TLR2 were increased. Nevertheless, this is not an indication that inflammatory responses were increased, since no immune system cells were present during the exposure. Further studies are necessary with an in vitro model that includes immune cells (e.g., organoid-immune cell co-culture) to better understand how intestinal epithelial cells represented by organoids communicate with the local immune system, resulting in gefitinib-induced acute and/or chronic inflammation clinically.

Moreover, exposure to gefitinib had an impact on metabolism in both types of organoids (Table S2). Overall, energy production metabolic pathways including glycolysis, TCA cycle, pyruvate metabolism and respiratory electron chain/AT synthesis were more perturbed in colon organoids. DEGs involved in these pathways were mostly downregulated, reflecting the negative effect of gefitinib on the cells' energy balance. In turn, effects on drug metabolism mediated by CYP450 were more prominent in SI organoids, particularly with the upregulation of CYP3A5. CYP450 enzymes play an important role in gefitinib metabolism and its clearance, lowering the drug's concentration and, consequently, increasing resistance to the drug [4]. Noteworthily, studies have reported that protein levels of CYP3A are generally higher in SI than in colon $[44,45]$. Therefore, this could explain SI organoids lower sensitivity to gefitinib as compared with colon organoids. Metabolism of proteins, amino acids and lipids, as well as cholesterol biosynthesis were significantly affected in both types of organoids, but exposure concentration seemed to have more impact in colon whereas time of exposure had more impact in SI. An interesting finding was the different expression profiles of DEGs involved in the metabolism of lipids, important for energy production, and cholesterol biosynthesis, an essential component of cell membranes [46]. In colon, genes were clearly downregulated whereas in SI they were upregulated. After further investigation, we found that expression levels of PRKAB1, 
encoding for the regulatory subunit of AMPK and thus regulating its function, were upregulated in colon and downregulated in SI. AMPK is known to become activated and supress cell growth when cells are in stress and energy balance needs to be restored [47]. One of AMPK's roles in response to cellular metabolic stresses is to phosphorylate and inactivate acetyl-CoA carboxylase (ACC) and $\beta$-hydroxy- $\beta$-methylglutaryl-CoA reductase (HMGCR), which are key enzymes of the biosynthesis of lipids and cholesterol, respectively [47]. Therefore, this is a strong indicator that AMPK activity was regulated differently in colon and SI due to PRKAB1 expression, resulting in opposite metabolism of lipids and cholesterol. In addition, levels of CYP51A1 and ABCA1 were also opposite in the two different organoid models (Table 3 ), suggesting that cholesterol biosynthesis might be activated in SI in contrast to the colon where the efflux of cholesterol is enhanced.

Taken all together, these results show that colon organoids were more sensitive to exposure to gefitinib as compared with SI organoids, and the colon is therefore more likely to be damaged and lose epithelial integrity. This negative impact on the integrity of the colon's epithelial barrier may explain the clinical side effects of gefitinib, namely diarrhoea. On the other hand, SI organoids seemed to possess a mechanism to better resist gefitinib's effects by increasing cholesterol synthesis, unlike colon. In fact, some studies have reported that higher levels of cholesterol in the cellular membrane where EGFR is located, is associated with less sensitivity to gefitinib [48-50]. This novel finding brings promise to the improvement of cancer therapies in which increase of cholesterol levels in the colon tissue via co-administration may protect against the drug's toxicity.

Future studies including organoids derived from different donors and patients, as well as measurement of protein levels involved in key response mechanisms identified in this study, are needed to confirm these results and if they are indeed tissue-specific or donorspecific. Nevertheless, generating healthy colon and SI organoids from the same individual remains either an ethical challenge, as donors would need to undergo unnecessary surgical procedures, or a commercial one, as paired organoid models are not available yet. Once these challenges are overcome, the inclusion of paired healthy colon and SI organoids will be possible in future studies, so that donor genetic background variability, which influences drug-gene responses, is investigated. Moreover, transcriptomic data generated from intestinal tissue biopsies of cancer patients taking gefitinib as treatment is important to validate the molecular mechanisms of gefitinib-induced intestinal toxicity in the organoids. Well-validated markers of toxicity may eventually be applied in clinical settings to inform personalized therapies aiming to reduce the severity of drug-induced side effects. The new data generated from this study holds promise in supporting the development of tools to assess drug safety and de-risking strategies for novel therapeutic candidates before entering first-in-human trials. Furthermore, this data will be integrated in the development of computational GI drug toxicity prediction models being developed in the context of the transQST project [26].

\section{Materials and Methods}

\subsection{Three-Dimensional In Vitro Culture of Human Healthy Intestinal Organoids}

Human healthy colon and small intestine (SI) organoids were kindly provided by Boehringer Ingelheim Pharmaceuticals Inc. (Ridgefield, CT, USA) who purchased two tissue biopsies collected from healthy 67- and 74-year-old male donors, respectively, by Discovery Life Sciences (formerly, Conversant Biologics Inc., Huntsville, AL, USA) under the bio-specimen purchase agreement. All tissue samples were collected with written informed consent under an approval of the institutional review board (IRB). Noteworthily, the choice of healthy male donors to generate the organoids was based on tissue availability and did not consider the prevalence of adverse effects caused by gefitinib experienced by male and female patients. Cultivation and differentiation of the colon and SI tissue models was adapted from the methods described by Sato et al. [39]. Frozen organoids were recovered on a 24-well plate and grown in complete crypt medium [14] in order to maintain a stem cell state for propagation. Colon and SI cultures were passaged every 3-7 days as 
described in our previous work [14]. Prior to experimentation, organoids were transferred to 96-well plates and cultured in Human IntestiCult ${ }^{\mathrm{TM}}$ Organoid Growth Medium (Stemcell, Cologne, Germany) to promote cell differentiation. After 2-3 days, organoids started to differentiate and to exhibit intestine-like crypts and villi [14].

\subsection{Selection of Gefitinib In Vitro Concentrations Based on PBPK Simulation}

The Simcyp ${ }^{\circledR}$ simulator (Version 19 release 1; Certara UK Ltd., Sheffield, UK) was used to develop and verify a model describing human gefitinib pharmacokinetics (PK) following oral dosing based on gefitinib physiochemical properties and relevant absorption, distribution, metabolism, and excretion (ADME) properties. The advanced dissolution, absorption, and metabolism (ADAM) model [51,52] was used to predict gefitinib concentrations in enterocytes in addition to concentrations in plasma. The details of parameters and sources used are listed in Table S1. The data used to verify the model performance [27] were not used for model parameterisation. The verified gefitinib PBPK model was then used to predict plasma and jejunum enterocyte drug concentrations in healthy volunteers (aged $20-50$ years old, $50 \%$ female, $n=100$ ) after the therapeutic regimen of once daily $250 \mathrm{mg}$ oral dose [28], over the course of 14 days.

Simcyp's in vitro data analysis toolkit (SIVA Version 3, module 3; Certara UK Ltd., Sheffield, UK) for virtual in vitro distribution (VIVD) [53] was used to simulate the distribution of gefitinib in human intestinal organoids in vitro based on gefitinib physiochemical properties, experimental design, and intestinal cell composition from Simcyp V19r1. In vitro nominal gefitinib concentrations that achieved intracellular concentrations equivalent to those predicted using PBPK was explored. The input parameters for this model are detailed in Table S1.

\subsection{Design of In Vitro Exposure to Gefitinib}

Gefitinib was purchased from Merck (Darmstadt, Germany), with $\geq 99 \%$ purity. Selection of gefitinib concentrations was based on the PBPK calculation methods described above. After 3 days in Human IntestiCult Growth medium, differentiated intestinal organoids were exposed to $100 \mu \mathrm{L}$ of medium containing $0.1 \mu \mathrm{M}, 1 \mu \mathrm{M}, 10 \mu \mathrm{M}$ and $30 \mu \mathrm{M}$ gefitinib for $24 \mathrm{~h}, 48 \mathrm{~h}$ and $72 \mathrm{~h}$. Controls containing only IntestiCult medium (untreated controls) and IntestiCult medium with $0.1 \%$ DMSO (vehicle controls) were included for all time points. All treatment conditions were performed in biological triplicates in 96-well plates. The remaining wells were filled with $100 \mu \mathrm{L}$ PBS to eliminate possible edge effects. For all treatment conditions, samples were collected to evaluate toxicity assays and perform RNA sequencing.

\subsection{Cytotoxicity Assays: ATP-Based Viability and Caspase 3/7 Activity Evaluation}

Cytotoxicity endpoints for viability and caspase $3 / 7$ activity were measured with 3D Celltiter-Glo and Caspase-Glo 3/7 (Promega, Madison, WI, USA), respectively, per manufacturer's instructions. These endpoints were used to evaluate the toxicity profile of gefitinib and to check if they were reflected on the transcriptomic data. After each time point of exposure, medium was removed and replaced by $100 \mu \mathrm{L}$ of either kit reagent to the appropriate wells and well homogenized. The plates were placed in a Scilogex MX-M 96 well plate shaker for $1 \mathrm{~h}$ at room temperature. Afterwards, samples were transferred to white opaque 96-well plates (Corning, NY, USA) to measure luminescence values in GloMax ${ }^{\circledR} 96$ Microplate Luminometer (Promega, Madison, WI, USA). Luminescence values were transferred to GraphPad Prism 9.0 (GraphPad Software, San Diego, CA, USA), normalized to the respective time-controls, and corrected for the blank reaction to eliminate possible interferences of the matrigel in the absorbance. Statistical differences between conditions were calculated by applying the analysis of variance (ANOVA) test. 


\subsection{Image Analysis of Morphological Changes}

Colon and SI organoids were grown and treated with the same conditions as described previously, after which changes in morphology and structure of the cells were analysed. This analysis aimed to support the cytotoxicity evaluation and to provide insight into significant structural changes associated with gefitinib's mechanism of toxicity. After each time point, fixation in 3\% Formaldehyde and staining were performed to visualize the nuclei (in blue) and actin cytoskeleton (in red), by applying a solution containing Hoechst 33258 (Merck, Darmstadt, Germany) with a final concentration of $0.4 \mu \mathrm{g} / \mathrm{mL}$, and Rhodamine-phalloidin (Merck, Darmstadt, Germany), with final concentration of $0.1 \mu \mathrm{M}$ [54]. Images were captured as z-stacks in an ImageXpress Micro XLS (Molecular Devices, Silicon Valley, CA, USA) wide field microscope, using the $4 \times$ objective, and analysed in the 3D image analysis solution Ominer ${ }^{\circledR}$ (Crown Bioscience Netherlands B.V., Leiden, the Netherlands). GraphPad Prism 9.0 (GraphPad Software, San Diego, CA, USA) was used to obtain values for average organoids size, roundness and dead cells. The treatment values were normalized to the respective time-controls.

\subsection{RNA Isolation and Quantification}

For each treatment condition, medium was removed and $200 \mu \mathrm{L}$ of QIazol Lysis reagent (Qiagen, Venlo, The Netherlands) was added into each well, in which the matrigel was dissociated to collect each pellet. This process was repeated twice, ensuring collection of all organoids as well as ensuring a total volume of $700 \mu \mathrm{L}$ of QIazol Lysis reagent in each tube containing pellet. An extra vigorous pipetting and vortex was performed to allow complete homogenization of organoids in the lysis reagent. RNA isolation and purification were performed using the miRNeasy Mini Kit (Qiagen, Venlo, The Netherlands), following manufacturer's protocol for Animal Cells including a DNase treatment. Total RNA yield was measured on Nanodrop ${ }^{\circledR}$ ND-1000 spectrophotometer (Thermo Fisher Scientific, Waltham, MA, USA). RNA quality was checked with RNA Nanochips or Picochips on a 2100 Bioanalyzer (Agilent Technologies, Leuven, Belgium). All samples presented integrity number (RIN) $>7.5$ and average RNA yield of $607 \mathrm{ng}$, for colon samples, and $262 \mathrm{ng}$, for SI samples.

\subsection{Library Preparation and $m R N A$ Sequencing}

Purified RNA from each sample was prepared for sequencing using the Lexogen SENSE mRNA library preparation kit (Lexogen, Vienna, Austria), following the manufacturer's instructions. Quality checks were assessed for every library. Afterwards, the samples were sequenced on the NovaSeq 6000 system (Illumina, Eindhoven, The Netherlands). A pool of all treated and untreated samples was sequenced on the two lanes of a S1 flow cell. The average gene count was 14.58 million raw reads.

\subsection{Data Processing and Analysis}

The first step of pre-processing consisted in the removal of the 12 bases of the $5^{\prime}$ end of all reads, which correspond to the Lexogen adapter sequences, using Trimmomatic version 0.33 [55]. Before and after this trimming step, the quality of the sequencing data was confirmed using FastQC version 0.11.3 [56] and only samples that met the required parameters were used for subsequent analysis. Following trimming and $\mathrm{QC}$ check, gene reads were aligned to the complete human genome (Ensembl build v. 93 GRCh38) using Bowtie 1.1.1 and quantified with RSEM 1.3.1, with an average of 10 million reads per sample. Normalization of the quantified read counts from all samples was performed using the R package DESeq 2 (v. 1.14.1) (Bioconductor, Seattle, WA, USA) [57] resulting in a list of around 13,000 differentially expressed genes (DEGs) for each treatment condition. Moreover, the profile and distribution of the samples were obtained according to the amount of reads, hierarchical clustering, principal component analysis (PCA) and sample dispersion. For each time point, the following comparisons were possible: (a) Untreated control vs. Vehicle control; (b) $0.1 \mu \mathrm{M}$ vs. Vehicle control; (c) $1 \mu \mathrm{M}$ vs. Vehicle control; (d) $10 \mu \mathrm{M}$ 
vs. Vehicle control; (e) $30 \mu \mathrm{M}$ vs. Vehicle control. In addition, Bonferroni correction [30] was applied to all genes obtained, after which genes with adjusted $p$-value $<0.05$ were considered as differential expressed genes (DEGs).

\subsection{Pathway Analysis Based on DEGs}

The lists of DEGs obtained for each time point and concentration were used as input for pathway overrepresentation analysis (ORA) using ConsensusPathDB (CPDB) release 34 [58], considering a cut-off of 0.01 . ORA analysis provided an overview of biological pathways affected in treated samples as compared to vehicle controls. The Reactome database version 67 [59], WikiPathways [60] and KEGG [61] were selected as preferred databases for pathway analysis and interpretation of biological processes. The most significantly overrepresented pathways were identified using the q-values $(q<0.05)$ and the number of DEGs involved. The most relevant DEGs we visually summarised using BioRender illustration tool [62].

Supplementary Materials: The following supporting information can be downloaded at: https: / / www.mdpi.com/article/10.3390/ijms23042213/s1, References [28,29,53,63-70] are cited in the Supplementary Materials.

Author Contributions: D.R. was responsible for the design and execution of experimental work (culture of colon organoids, exposure experiments, cytotoxicity assays, RNA isolation and RNAseq libraries) and transcriptomics data analysis. D.G.J.J. supported transcriptomic data analysis. B.H. was responsible for experimental work regarding culture of small intestine organoids and exposure experiments with SI organoids and assisted with the image analysis technology. S.F., H.J. and C.F. contributed to the PBPK simulations. L.C. and S.-W.C. contributed with their expertise in organoid cultures and data analysis, respectively. T.M.d.K. and J.C.S.K. helped with the study design and supervision. D.R. wrote this manuscript with input of all co-authors, especially J.C.S.K., D.G.J.J. and T.M.d.K. All co-authors had access to the study data. All authors have read and agreed to the published version of the manuscript.

Funding: The transQST project was funded by the Innovative Medicines Initiative 2 Joint Undertaking under grant agreement No 116030. This Joint Undertaking receives support from the European Union's Horizon 2020 research and innovation programme and EFPIA.

Institutional Review Board Statement: Human intestinal tissue samples were obtained by Boehringer Ingelheim Pharmaceuticals Inc. (Ridgefield, CT, USA) from Discovery Life Sciences (Huntsville, AL, USA; formerly, Conversant Biologics Inc.) under a bio-specimen purchase agreement.

Informed Consent Statement: All samples were collected with the written informed consent under an approval of the institutional review board (IRB).

Data Availability Statement: The cytotoxicity data generated and analysed during the current study are available in the BioStudies repository (www.ebi.ac.uk/biostudies/studies/S-TQST115). The transcriptomic data generated and analysed during the current study will be publicly available on ArrayExpress repository (www.ebi.ac.uk/arrayexpress/) with accession number E-MTAB-11221.

Acknowledgments: The authors thank Aaron Kalark (Boehringer Ingelheim) for providing initial organoid cultures and the technical guidance on them. The author would also like to thank Marcel van Herwijnen and Duncan Hauser for their technical support on the RNA sequencing.

Conflicts of Interest: The authors declare no conflict of interest. The funders had no role in the design of the study; in the collection, analyses, or interpretation of data; in the writing of the manuscript, or in the decision to publish the results.

Disclaimer: Authors declare that this work reflects only the author's views, and that IMI-JU is not responsible for any use that may be made of the information it contains.

\section{References}

1. Yaish, P.; Gazit, A.; Gilon, C.; Levitzki, A. Blocking of EGF-dependent cell proliferation by EGF receptor kinase inhibitors. Science 1988, 242, 933-935. [CrossRef]

2. Rawluk, J.; Waller, C.F. Gefitinib. Recent Results Cancer Res. 2018, 211, 235-246. [CrossRef] [PubMed] 
3. Hartmann, J.T.; Haap, M.; Kopp, H.G.; Lipp, H.P. Tyrosine kinase inhibitors-A review on pharmacology, metabolism and side effects. Curr. Drug Metab. 2009, 10, 470-481. [CrossRef] [PubMed]

4. Zhao, C.; Han, S.Y.; Li, P.P. Pharmacokinetics of Gefitinib: Roles of Drug Metabolizing Enzymes and Transporters. Curr. Drug Deliv. 2017, 14, 282-288. [CrossRef] [PubMed]

5. William, W.N., Jr.; Feng, L.; Ferrarotto, R.; Ginsberg, L.; Kies, M.; Lippman, S.; Glisson, B.; Kim, E.S. Gefitinib for patients with incurable cutaneous squamous cell carcinoma: A single-arm phase II clinical trial. J. Am. Acad. Dermatol. 2017, 77, 1110-1113.e2. [CrossRef] [PubMed]

6. Goncalves, A.; Fabbro, M.; Lhomme, C.; Gladieff, L.; Extra, J.M.; Floquet, A.; Chaigneau, L.; Carrasco, A.T.; Viens, P. A phase II trial to evaluate gefitinib as second- or third-line treatment in patients with recurring locoregionally advanced or metastatic cervical cancer. Gynecol. Oncol. 2008, 108, 42-46. [CrossRef] [PubMed]

7. Kobayashi, H.; Sato, K.; Niioka, T.; Takeda, M.; Okuda, Y.; Asano, M.; Ito, H.; Miura, M. Effects of polymorphisms in CYP2D6 and $\mathrm{ABC}$ transporters and side effects induced by gefitinib on the pharmacokinetics of the gefitinib metabolite, O-desmethyl gefitinib. Med. Oncol. 2016, 33, 57. [CrossRef]

8. Hare, K.J.; Hartmann, B.; Kissow, H.; Holst, J.J.; Poulsen, S.S. The intestinotrophic peptide, glp-2, counteracts intestinal atrophy in mice induced by the epidermal growth factor receptor inhibitor, gefitinib. Clin. Cancer Res. 2007, 13, 5170-5175. [CrossRef]

9. Burotto, M.; Manasanch, E.E.; Wilkerson, J.; Fojo, T. Gefitinib and Erlotinib in Metastatic Non-Small Cell Lung Cancer: A Meta-Analysis of Toxicity and Efficacy of Randomized Clinical Trials. Oncologist 2015, 20, 400-410. [CrossRef]

10. Takeda, M.; Nakagawa, K. Toxicity profile of epidermal growth factor receptor tyrosine kinase inhibitors in patients with epidermal growth factor receptor gene mutation-positive lung cancer (Review). Mol. Clin. Oncol. 2017, 6, 3-6. [CrossRef]

11. Ho, C.; Davis, J.; Anderson, F.; Bebb, G.; Murray, N. Side effects related to cancer treatment: CASE 1. Hepatitis following treatment with gefitinib. J. Clin. Oncol. 2005, 23, 8531-8533. [CrossRef]

12. Kumasaka, R.; Nakamura, N.; Shirato, K.; Osawa, H.; Takanashi, S.; Hasegawa, Y.; Yamabe, H.; Nakamura, M.; Tamura, M.; Okumura, K. Side effects of therapy: Case 1. Nephrotic syndrome associated with gefitinib therapy. J. Clin. Oncol. 2004, 22, 2504-2505. [CrossRef]

13. Herbst, R.S.; LoRusso, P.M.; Purdom, M.; Ward, D. Dermatologic side effects associated with gefitinib therapy: Clinical experience and management. Clin. Lung Cancer 2003, 4, 366-369. [CrossRef]

14. Rodrigues, D.; de Souza, T.; Coyle, L.; Di Piazza, M.; Herpers, B.; Ferreira, S.; Zhang, M.; Vappiani, J.; Sevin, D.C.; Gabor, A.; et al New insights into the mechanisms underlying 5-fluorouracil-induced intestinal toxicity based on transcriptomic and metabolomic responses in human intestinal organoids. Arch. Toxicol. 2021, 95, 2691-2718. [CrossRef]

15. Chaicharoenaudomrung, N.; Kunhorm, P.; Noisa, P. Three-dimensional cell culture systems as an in vitro platform for cancer and stem cell modeling. World J. Stem Cells 2019, 11, 1065-1083. [CrossRef]

16. Nii, T.; Makino, K.; Tabata, Y. Three-Dimensional Culture System of Cancer Cells Combined with Biomaterials for Drug Screening. Cancers 2020, 12, 2754. [CrossRef]

17. Sato, T.; Vries, R.G.; Snippert, H.J.; van de Wetering, M.; Barker, N.; Stange, D.E.; van Es, J.H.; Abo, A.; Kujala, P.; Peters, P.J.; et al. Single Lgr5 stem cells build crypt-villus structures in vitro without a mesenchymal niche. Nature 2009, 459, 262-265. [CrossRef]

18. Zachos, N.C.; Kovbasnjuk, O.; Foulke-Abel, J.; In, J.; Blutt, S.E.; de Jonge, H.R.; Estes, M.K.; Donowitz, M. Human Enteroids/Colonoids and Intestinal Organoids Functionally Recapitulate Normal Intestinal Physiology and Pathophysiology. J. Biol. Chem. 2016, 291, 3759-3766. [CrossRef]

19. Fatehullah, A.; Tan, S.H.; Barker, N. Organoids as an in vitro model of human development and disease. Nat. Cell Biol. 2016, 18, 246-254. [CrossRef]

20. Kim, J.; Koo, B.K.; Knoblich, J.A. Human organoids: Model systems for human biology and medicine. Nat. Rev. Mol. Cell Biol. 2020, 21, 571-584. [CrossRef]

21. Pain, B.; Baquerre, C.; Coulpier, M. Cerebral organoids and their potential for studies of brain diseases in domestic animals. Vet. Res. 2021, 52, 65. [CrossRef]

22. Plummer, S.; Wallace, S.; Ball, G.; Lloyd, R.; Schiapparelli, P.; Quinones-Hinojosa, A.; Hartung, T.; Pamies, D. A Human iPSCderived 3D platform using primary brain cancer cells to study drug development and personalized medicine. Sci. Rep. 2019, 9, 1407. [CrossRef]

23. Kim, M.; Mun, H.; Sung, C.O.; Cho, E.J.; Jeon, H.J.; Chun, S.M.; Jung, D.J.; Shin, T.H.; Jeong, G.S.; Kim, D.K.; et al. Patient-derived lung cancer organoids as in vitro cancer models for therapeutic screening. Nat. Commun. 2019, 10, 3991. [CrossRef] [PubMed]

24. Nunes, A.S.; Costa, E.C.; Barros, A.S.; de Melo-Diogo, D.; Correia, I.J. Establishment of 2D Cell Cultures Derived from 3D MCF-7 Spheroids Displaying a Doxorubicin Resistant Profile. Biotechnol. J. 2019, 14, e1800268. [CrossRef] [PubMed]

25. Devarasetty, M.; Skardal, A.; Cowdrick, K.; Marini, F.; Soker, S. Bioengineered Submucosal Organoids for In Vitro Modeling of Colorectal Cancer. Tissue Eng. Part A 2017, 23, 1026-1041. [CrossRef] [PubMed]

26. Ferreira, S.; Fisher, C.; Furlong, L.I.; Laplanche, L.; Park, B.K.; Pin, C.; Saez-Rodriguez, J.; Trairatphisan, P. Quantitative Systems Toxicology Modeling to Address Key Safety Questions in Drug Development: A Focus of the TransQST Consortium. Chem. Res. Toxicol. 2020, 33, 7-9. [CrossRef] [PubMed]

27. Swaisland, H.C.; Ranson, M.; Smith, R.P.; Leadbetter, J.; Laight, A.; McKillop, D.; Wild, M.J. Pharmacokinetic drug interactions of gefitinib with rifampicin, itraconazole and metoprolol. Clin. Pharmacokinet. 2005, 44, 1067-1081. [CrossRef] 
28. Astrazeneca. 2015. Available online: https://www.accessdata.fda.gov/drugsatfda_docs/label/2018/206995s003lbl.pdf (accessed on 5 March 2019).

29. Chen, Y.; Zhou, D.; Tang, W.; Zhou, W.; Al-Huniti, N.; Masson, E. Physiologically Based Pharmacokinetic Modeling to Evaluate the Systemic Exposure of Gefitinib in CYP2D6 Ultrarapid Metabolizers and Extensive Metabolizers. J. Clin. Pharmacol. 2018, 58, 485-493. [CrossRef]

30. Aickin, M.; Gensler, H. Adjusting for multiple testing when reporting research results: The Bonferroni vs Holm methods. Am. J. Public Health 1996, 86, 726-728. [CrossRef]

31. Ariyama, H.; Qin, B.; Baba, E.; Tanaka, R.; Mitsugi, K.; Harada, M.; Nakano, S. Gefitinib, a selective EGFR tyrosine kinase inhibitor, induces apoptosis through activation of Bax in human gallbladder adenocarcinoma cells. J. Cell. Biochem. 2006, 97, 724-734. [CrossRef]

32. Li, H.; Zhou, S.; Li, X.; Wang, D.; Wang, Y.; Zhou, C.; Schmid-Bindert, G. Gefitinib-resistance is related to BIM expression in non-small cell lung cancer cell lines. Cancer Biother. Radiopharm. 2013, 28, 115-123. [CrossRef]

33. Hong, S.; Gu, Y.; Gao, Z.; Guo, L.; Guo, W.; Wu, X.; Shen, Y.; Sun, Y.; Wu, X.; Xu, Q. EGFR inhibitor-driven endoplasmic reticulum stress-mediated injury on intestinal epithelial cells. Life Sci. 2014, 119, 28-33. [CrossRef]

34. Fan, L.; Hu, L.; Yang, B.; Fang, X.; Gao, Z.; Li, W.; Sun, Y.; Shen, Y.; Wu, X.; Shu, Y.; et al. Erlotinib promotes endoplasmic reticulum stress-mediated injury in the intestinal epithelium. Toxicol. Appl. Pharmacol. 2014, 278, 45-52. [CrossRef]

35. Walters, J.R.; Tasleem, A.M.; Omer, O.S.; Brydon, W.G.; Dew, T.; le Roux, C.W. A new mechanism for bile acid diarrhea: Defective feedback inhibition of bile acid biosynthesis. Clin. Gastroenterol. Hepatol. 2009, 7, 1189-1194. [CrossRef]

36. Carter, M.E.; Brunet, A. FOXO transcription factors. Curr. Biol. 2007, 17, R113-R114. [CrossRef]

37. Pottier, C.; Fresnais, M.; Gilon, M.; Jerusalem, G.; Longuespee, R.; Sounni, N.E. Tyrosine Kinase Inhibitors in Cancer: Breakthrough and Challenges of Targeted Therapy. Cancers 2020, 12, 731. [CrossRef]

38. Mahe, M.M.; Aihara, E.; Schumacher, M.A.; Zavros, Y.; Montrose, M.H.; Helmrath, M.A.; Sato, T.; Shroyer, N.F. Establishment of Gastrointestinal Epithelial Organoids. Curr. Protoc. Mouse Biol. 2013, 3, 217-240. [CrossRef]

39. Sato, T.; Stange, D.E.; Ferrante, M.; Vries, R.G.; Van Es, J.H.; Van den Brink, S.; Van Houdt, W.J.; Pronk, A.; Van Gorp, J.; Siersema, P.D.; et al. Long-term expansion of epithelial organoids from human colon, adenoma, adenocarcinoma, and Barrett's epithelium. Gastroenterology 2011, 141, 1762-1772. [CrossRef]

40. Rodrigues, D.; Coyle, L.; Füzi, B.; Ferreira, S.; Jo, H.; Herpers, B.; Chung, S.-W.; Fisher, C.; Kleinjans, J.C.S.; Jennen, D.; et al. Unravelling Mechanisms of Doxorubicin-Induced Toxicity in 3D Human Intestinal Organoids. Int. J. Mol. Sci. 2022, 23, 1286. [CrossRef]

41. Ferrandiz, N.; Martin-Perez, J.; Blanco, R.; Donertas, D.; Weber, A.; Eilers, M.; Dotto, P.; Delgado, M.D.; Leon, J. HCT116 cells deficient in p21(Waf1) are hypersensitive to tyrosine kinase inhibitors and adriamycin through a mechanism unrelated to p21 and dependent on p53. DNA Repair. 2009, 8, 390-399. [CrossRef]

42. Busser, B.; Sancey, L.; Josserand, V.; Niang, C.; Favrot, M.C.; Coll, J.L.; Hurbin, A. Amphiregulin promotes BAX inhibition and resistance to gefitinib in non-small-cell lung cancers. Mol. Ther. 2010, 18, 528-535. [CrossRef]

43. Chen, J.; Lu, H.; Zhou, W.; Yin, H.; Zhu, L.; Liu, C.; Zhang, P.; Hu, H.; Yang, Y.; Han, H. AURKA upregulation plays a role in fibroblast-reduced gefitinib sensitivity in the NSCLC cell line HCC827. Oncol. Rep. 2015, 33, 1860-1866. [CrossRef]

44. Thelen, K.; Dressman, J.B. Cytochrome P450-mediated metabolism in the human gut wall. J. Pharm. Pharmacol. 2009, 61, 541-558. [CrossRef]

45. Iswandana, R.; Irianti, M.I.; Oosterhuis, D.; Hofker, H.S.; Merema, M.T.; de Jager, M.H.; Mutsaers, H.A.M.; Olinga, P. Regional Differences in Human Intestinal Drug Metabolism. Drug Metab. Dispos. 2018, 46, 1879-1885. [CrossRef] [PubMed]

46. Cerqueira, N.M.; Oliveira, E.F.; Gesto, D.S.; Santos-Martins, D.; Moreira, C.; Moorthy, H.N.; Ramos, M.J.; Fernandes, P.A. Cholesterol Biosynthesis: A Mechanistic Overview. Biochemistry 2016, 55, 5483-5506. [CrossRef]

47. Herzig, S.; Shaw, R.J. AMPK: Guardian of metabolism and mitochondrial homeostasis. Nat. Rev. Mol. Cell Biol. 2018, 19, 121-135. [CrossRef]

48. Irwin, M.E.; Mueller, K.L.; Bohin, N.; Ge, Y.; Boerner, J.L. Lipid raft localization of EGFR alters the response of cancer cells to the EGFR tyrosine kinase inhibitor gefitinib. J. Cell. Physiol. 2011, 226, 2316-2328. [CrossRef]

49. Chen, Q.; Pan, Z.; Zhao, M.; Wang, Q.; Qiao, C.; Miao, L.; Ding, X. High cholesterol in lipid rafts reduces the sensitivity to EGFR-TKI therapy in non-small cell lung cancer. J. Cell. Physiol. 2018, 233, 6722-6732. [CrossRef] [PubMed]

50. Howell, M.C.; Green, R.; Khalil, R.; Foran, E.; Quarni, W.; Nair, R.; Stevens, S.; Grinchuk, A.; Hanna, A.; Mohapatra, S.; et al. Lung cancer cells survive epidermal growth factor receptor tyrosine kinase inhibitor exposure through upregulation of cholesterol synthesis. FASEB Bioadv. 2020, 2, 90-105. [CrossRef] [PubMed]

51. Jamei, M.; Turner, D.; Yang, J.; Neuhoff, S.; Polak, S.; Rostami-Hodjegan, A.; Tucker, G. Population-based mechanistic prediction of oral drug absorption. AAPS J. 2009, 11, 225-237. [CrossRef] [PubMed]

52. Jamei, M.; Marciniak, S.; Feng, K.; Barnett, A.; Tucker, G.; Rostami-Hodjegan, A. The Simcyp population-based ADME simulator. Expert Opin. Drug Metab. Toxicol. 2009, 5, 211-223. [CrossRef]

53. Fisher, C.; Simeon, S.; Jamei, M.; Gardner, I.; Bois, Y.F. VIVD: Virtual in vitro distribution model for the mechanistic prediction of intracellular concentrations of chemicals in in vitro toxicity assays. Toxicol. In Vitro 2019, 58, 42-50. [CrossRef]

54. Di, Z.; Klop, M.J.; Rogkoti, V.M.; Le Devedec, S.E.; van de Water, B.; Verbeek, F.J.; Price, L.S.; Meerman, J.H. Ultra high content image analysis and phenotype profiling of 3D cultured micro-tissues. PLoS ONE 2014, 9, e109688. [CrossRef] 
55. Bolger, A.M.; Lohse, M.; Usadel, B. Trimmomatic: A flexible trimmer for Illumina sequence data. Bioinformatics 2014, 30, 2114-2120. [CrossRef]

56. Andrews, S. FastQC A Quality Control Tool for High Throughput Sequence Data. 2014. Available online: http://www. bioinformatics.babraham.ac.uk/projects/fastqc/ (accessed on 21 April 2021).

57. Love, M.I.; Huber, W.; Anders, S. Moderated estimation of fold change and dispersion for RNA-seq data with DESeq2. Genome Biol. 2014, 15, 550. [CrossRef]

58. Kamburov, A.; Stelzl, U.; Lehrach, H.; Herwig, R. The ConsensusPathDB interaction database: 2013 update. Nucleic Acids Res. 2013, 41, D793-D800. [CrossRef]

59. Fabregat, A.; Jupe, S.; Matthews, L.; Sidiropoulos, K.; Gillespie, M.; Garapati, P.; Haw, R.; Jassal, B.; Korninger, F.; May, B.; et al. The Reactome Pathway Knowledgebase. Nucleic Acids Res. 2018, 46, D649-D655. [CrossRef]

60. Martens, M.; Ammar, A.; Riutta, A.; Waagmeester, A.; Slenter, D.N.; Hanspers, K.; Miller, R.A.; Digles, D.; Lopes, E.N.; Ehrhart, F.; et al. WikiPathways: Connecting communities. Nucleic Acids Res. 2021, 49, D613-D621. [CrossRef]

61. Du, J.; Yuan, Z.; Ma, Z.; Song, J.; Xie, X.; Chen, Y. KEGG-PATH: Kyoto encyclopedia of genes and genomes-based pathway analysis using a path analysis model. Mol. Biosyst. 2014, 10, 2441-2447. [CrossRef]

62. BioRender. Available online: https:/ / biorender.com/ (accessed on 26 June 2021).

63. Information NCfB. PubChem Compound Summary for CID 123631, Gefitinib. Available online: https:/ / pubchem.ncbi.nlm.nih. gov / compound/Gefitinib (accessed on 30 November 2021).

64. Meylan WM, H.P. User's Guide for HENRYWIN Version 3.10: Henry's Law Constant Program; Syracuse Research Corporation: Syracuse, NY, USA, 2000.

65. Li, J.; Brahmer, J.; Messersmith, W.; Hidalgo, M.; Baker, S.D. Binding of gefitinib, an inhibitor of epidermal growth factor receptor-tyrosine kinase, to plasma proteins and blood cells: In vitro and in cancer patients. Investig. New Drugs 2006, 24, 291-297. [CrossRef]

66. Fink, C.; Sun, D.; Wagner, K.; Schneider, M.; Bauer, H.; Dolgos, H.; Mader, K.; Peters, S.A. Evaluating the Role of Solubility in Oral Absorption of Poorly Water-Soluble Drugs Using Physiologically-Based Pharmacokinetic Modeling. Clin. Pharmacol. Ther. 2020, 107, 650-661. [CrossRef]

67. Rodgers, T.; Leahy, D.; Rowland, M. Physiologically based pharmacokinetic modeling 1: Predicting the tissue distribution of moderate-to-strong bases. J. Pharm. Sci. 2005, 94, 1259-1276. [CrossRef]

68. Rodgers, T.; Rowland, M. Physiologically based pharmacokinetic modelling 2: Predicting the tissue distribution of acids, very weak bases, neutrals and zwitterions. J. Pharm. Sci. 2006, 95, 1238-1257. [CrossRef]

69. Ohno, Y.; Hisaka, A.; Ueno, M.; Suzuki, H. General framework for the prediction of oral drug interactions caused by CYP3A4 induction from in vivo information. Clin. Pharmacokinet. 2008, 47, 669-680. [CrossRef]

70. Fang, P.; Zheng, X.; He, J.; Ge, H.; Tang, P.; Cai, J.; Hu, G. Functional characterization of wild-type and 24 CYP2D6 allelic variants on gefitinib metabolism in vitro. Drug Des. Dev. Ther. 2017, 11, 1283-1290. [CrossRef] 